\title{
Recent Advances in the Brønsted/Lewis Acid Catalyzed Conversion of Glucose to HMF and Lactic Acid: Pathways toward Bio-Based Plastics
}

\author{
Cristina Megías-Sayago ${ }^{1, *}$, Sara Navarro-Jaén ${ }^{2, *(\mathbb{D}}$, Fabien Drault ${ }^{2}(\mathbb{D})$ and Svetlana Ivanova ${ }^{3}(\mathbb{D}$ \\ 1 Departamento de Ingeniería Química y Tecnologías del Medio Ambiente, Instituto de Nanociencia y \\ Materiales de Aragón (INMA), CSIC-Universidad de Zaragoza, 50018 Zaragoza, Spain \\ 2 Université de Lille, CNRS, Centrale Lille, Université d'Artois, UMR 8181-UCCS-Unité de Catalyse et \\ Chimie du Solide, F-59000 Lille, France; fabien.drault@univ-lille.fr \\ 3 Departamento de Química Inorgánica e Instituto de Ciencia de Materiales de Sevilla-Centro Mixto \\ CSIC/Universidad de Sevilla, Avda. Américo Vespucio, 49, 41092 Sevilla, Spain; svetlana@icmse.csic.es \\ * Correspondence: cristina.megias@icmse.csic.es (C.M.-S.); sara.navarro-jaen@univ-lille.fr (S.N.-J.)
}

check for

updates

Citation: Megías-Sayago, C.; Navarro-Jaén, S.; Drault, F.;

Ivanova, S. Recent Advances in the

Brønsted/Lewis Acid Catalyzed

Conversion of Glucose to HMF and Lactic Acid: Pathways toward Bio-Based Plastics. Catalysts 2021, 11, 1395. https://doi.org/10.3390/ catal11111395

Academic Editor: Filipa Ribeiro

Received: 31 October 2021

Accepted: 16 November 2021

Published: 18 November 2021

Publisher's Note: MDPI stays neutral with regard to jurisdictional claims in published maps and institutional affiliations.

Copyright: (c) 2021 by the authors. Licensee MDPI, Basel, Switzerland. This article is an open access article distributed under the terms and conditions of the Creative Commons Attribution (CC BY) license (https:// creativecommons.org/licenses/by/ $4.0 /)$.

\begin{abstract}
One of the most trending topics in catalysis recently is the use of renewable sources and/or non-waste technologies to generate products with high added value. That is why, the present review resumes the advances in catalyst design for biomass chemical valorization. The variety of involved reactions and functionality of obtained molecules requires the use of multifunctional catalyst able to increase the efficiency and selectivity of the selected process. The use of glucose as platform molecule is proposed here and its use as starting point for biobased plastics production is revised with special attention paid to the proposed tandem Bronsted/Lewis acid catalysts.
\end{abstract}

Keywords: bioplastic; biobased polymers; lactic acid; 5-hydroxymethylfurfural; glucose conversion

\section{Introduction}

Societal development is inevitably linked to an ever-growing energy demand. Over the last 150 years, the increasing energy demand has been covered by non-renewable fossil feedstocks which has consolidated the current scenario. The industry and, consequently, the global economy are driven by a unique linear model which has the days numbered. The almost imminent depletion of fossil fuels along with the environmental problems derived from their use are leading governments to adopt severe restrictions which forces somehow the scientific community to develop sustainable alternatives.

Plastic sector is part of the mentioned linear economy which starts with fossil feedstocks processing, plastic manufacture, plastic use and its final disposal as waste in landfills occasionally incinerated [1]. In addition to the massive amount of generated wastes (estimated to be $75 \%$ of the total plastic production i.e., $300 \mathrm{Mt} /$ year worldwide), plastic demand is increasing quickly in the last years due to their unique functional properties, wide range of applications, and low cost [2]. Indeed, its production is predicted to be four times higher in just 30 years [1] which appears completely incompatible not only with the existing environmental concerns and fossil feedstocks depletion but also with the current economic system.

Energy transition from fossil fuels to renewables is imperative to drive our society to a sustainable and environmentally friendly circular economy. Indeed, promoting plastics production from renewable resources has been identified as one of the three key areas of intervention to drive plastics within a circular model [3,4]. It should be noted that "biobased plastics" refer to any polymer family whose carbon source come from biological feedstocks such as biomass, but the term "bio" does not assure its biodegradability. In fact, a biobased plastic might not be biodegradable [5] while a fossil-based one might be. In this 
sense, it is worth to point out that the common-used word "bioplastic" refers either to its carbon source or to its biodegradability [2].

The catalytic transformation of biomass to high value-added chemicals and fuels has been outlined due to its environmental and economic advantages [6]. Nevertheless, the transition toward the biorefinery concept requires the design of active, selective, and stable catalysts [7]. Consequently, a huge amount of research in the last two decades has been devoted to elucidating catalysts' physicochemical properties [8]. Both Brønsted and Lewis acid sites have been demonstrated to play a pivotal role in the selective transformation to biomass-derived products, the control of the acid-base properties being the cornerstone of an efficient catalytic behavior. Among the different valuable chemicals from biomass, 5-hydroxymethylfurfural (HMF) and lactic acid (LaA) are considered as the most important intermediates to produce two biobased plastics [3], polyethylene 2,5-furandicarboxylate (PEF) and polylactic acid (PLA), respectively (Figure 1).
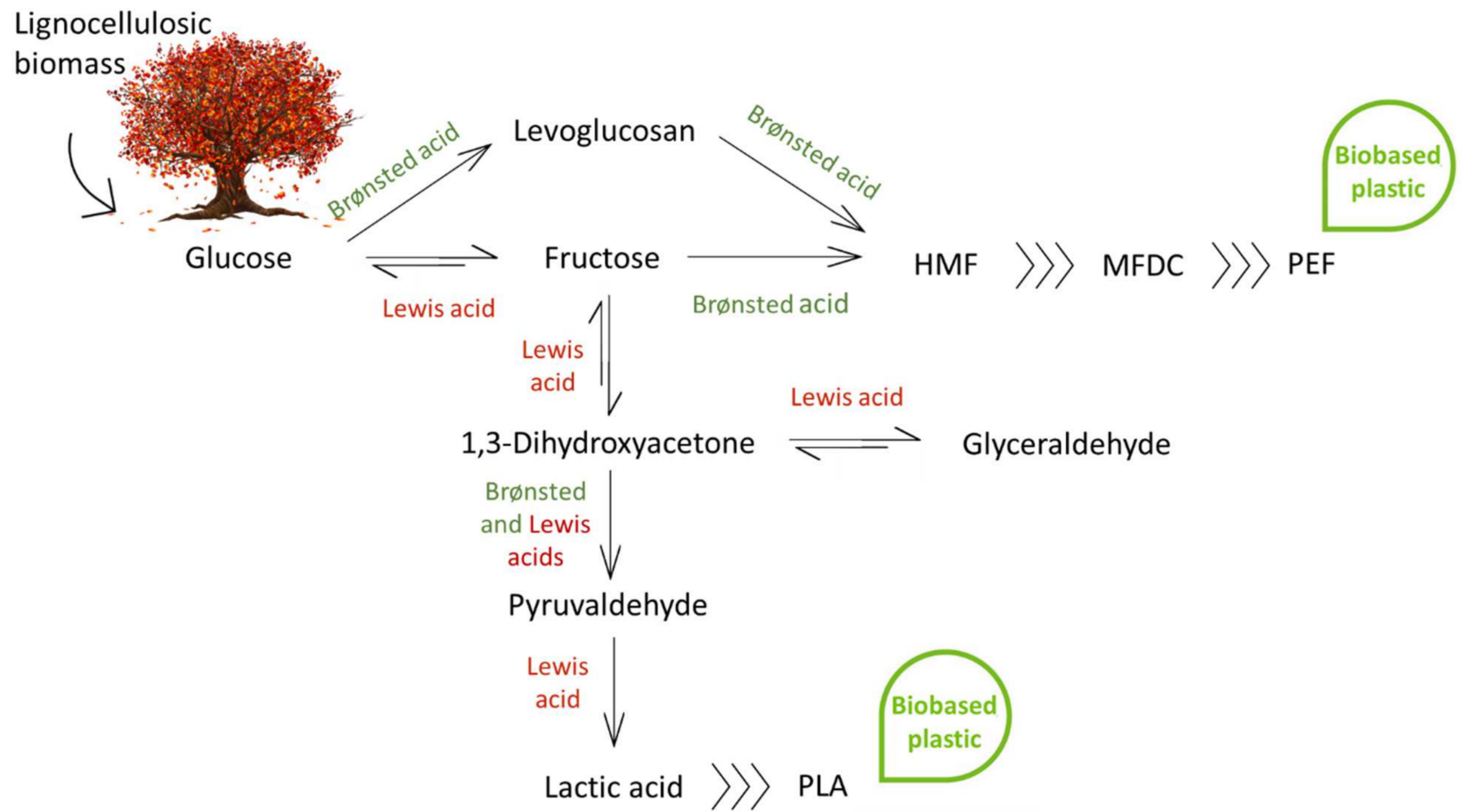

Figure 1. Brønsted/Lewis acid-catalyzed conversion of glucose to HMF and lactic acid.

The production of PEF goes through the polycondensation of two biobased monomers, methylfuran-2,5-dicarboxylate (MFDC), obtained after the oxidative esterification of HMF, and ethylene glycol [9]. PEF has been demonstrated to possess even superior thermal, physical, and mechanical properties to those corresponding to its fossil-based analogue, polyethylene terephthalate (PET) [10], a polymer widely used in many applications ranging from food/beverage packaging (especially convenience-sized soft drinks, juices and water), films, fabrics to molded parts for automotive and electronics. In addition to those improved properties, PEF has better barrier properties and higher tensile strength than PET which makes this bioplastic a better recyclable product since fewer additives are required [9].

The polycondensation of lactic acid, for its part, leads to the formation of a highly promising biodegradable and biocompatible polymer, PLA [11]. This bioplastic stands out as a potential alternative for petroleum-based plastics due to its excellent mechanical properties [12] and biodegradation and has been recently approved by the US Food and Drug Administration (FDA) for implantation in the human body, facilitating tissue recovery and eliminating the need of metallic implants removal [13,14].

Large-scale production of both biopolymers is strongly limited by the high price of their corresponding monomeric units, which is intrinsically related to the inexistence of eco- 
nomically viable processes and catalysts up to date. Despite the complex cascade reactions involved in bioplastics production and different active sites required (see Figure 1), the scientific community efforts yield promising results locating us closer to more sustainable world. For all the above, the present contribution will try to gather the latest advances in design and properties modification of Brønsted and/or Lewis acid catalysts for biomass upgrading in all steps included in the conversion of glucose (other feedstocks will be also contemplated) to HMF and lactic acid.

\section{Glucose Isomerization to Fructose}

Although apparently simple, glucose to fructose isomerization (Figure 2) is a key process for lignocellulosic biomass valorization to fuels and chemicals. The lignocellulosic biomass comprises cellulose as the main component, the exact percentage being strongly dependent on the biomass source and composed from a few hundred to over ten thousand glucose units [15]. This along with cellulose abundance and accessibility converts glucose in the most abundant and cheapest monosaccharide available.

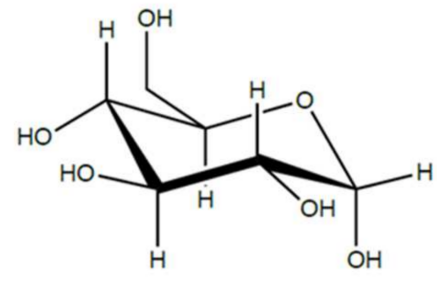

Glucose

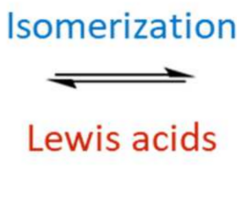

Lewis acids

Fructose

Figure 2. Glucose/fructose isomerization equilibrium.

The main route to produce 5-hydroxymethylfurfural and lactic acid from glucose involves as first step the isomerization to fructose (see Figure 1), the good performance of the equilibrium being determinant to achieve acceptable yields. This reaction is slightly endothermic $\left(\Delta \mathrm{H}=2.78 \mathrm{~kJ} \cdot \mathrm{mol}^{-1}\right)$ and is usually carried out at low temperatures, the equilibrium constant $\mathrm{K}_{\text {eq }}$ ranging from 1.1 to 1.5 within 70 to $120{ }^{\circ} \mathrm{C}$ temperature interval [16]. Glucose isomerization is industrially catalyzed by an immobilized enzyme at $60{ }^{\circ} \mathrm{C}$ resulting in $42 \%$ fructose yield [17]. Despite the good performances, enzymatic catalysts are highly expensive and require strict operation conditions such as narrow $\mathrm{pH}$ and temperature range and reactant purification, fact that makes the large-scale production of chemicals and fuels from glucose difficult [16].

Contrary to enzymatic, chemo-catalytic process involves the use of less expensive inorganic compounds able to operate under a broader range of reaction conditions and resulting industrially feasible to treat large amounts of glucose. Consequently, considerable efforts have been done to improve fructose selectivity and yield over different homogeneous/heterogeneous catalytic systems. The heterogeneous catalysts are clearly preferred mainly due to their easiness of separation from post reaction mixture along with the possibility of reuse in consecutive reaction cycles following a simple protocol. Regarding the involved sites, Lewis acid and more recently Lewis/Brønsted tandem catalysts have been applied. As a consequence, the newest advances are devoted to the tandem system with the principal aim to simplify the biomass valorization processes (the development of Lewis/Brønsted acid catalysts for glucose isomerization, aims to enable the one-pot conversion of glucose to HMF). Nevertheless, Lewis acid catalysts have been the subject of important research in the last five years.

The most studied and efficient Lewis acid catalysts are the substituted BETA zeolites and, more specifically, tin-containing ones [18-20]. Recent studies are devoted to improve Sn-BETA zeolites' performance by elucidating the causes of its deactivation [21] and by evaluating the effect of different modification treatments [22]. In this sense, Cordon et al. [21] revealed that the deactivation phenomena was related with the existence of silanol defect 
groups located within the microporous environments that are able to stabilize extended water networks. Higher water densities forming hydrogen bonded networks can entropically destabilize the $\mathrm{H} 2-\mathrm{H} 1$ hydride shift transition state which is the generally accepted mechanism of glucose isomerization over Lewis acid sites. Hierarchical Sn-Beta zeolites with intra-crystalline mesoporous structure have been also reported [22]. The authors observed higher catalytic activities compared to the microporous homologues which was attributed to the more efficient diffusion of reactant/product molecules.

Apart from zeolites, two other materials can be clearly identified in the last five years: (i) metal-organic frameworks (MOFs) and (ii) functionalized biochars. Both have drawn significant attention due to their tunable properties and density of active sites, being the main limitation of MOFs their poor thermal and chemical stability [23]. Zirconium-based $\mathrm{UiO}-66$ is one of the MOFs with the highest reported stability [23] with Zr clusters acting as Lewis acid sites [24]. Lately, UiO-66 has been modified by introducing Brønsted acid sites [24,25] achieving high fructose selectivity of approximately $90 \%$ for glucose to fructose and HMF conversion. The selectivity obtained over these dual Lewis/Brønsted acid MOFs is certainly close to that shown by Sn-beta zeolite. Zr-containing MOFs with MOF-808 and UiO-66 structures have been carefully compared [26], the kinetic and computational studies revealing an interesting structure-activity relationship.

Chromium-based MIL-101 MOF has been also recently proposed for glucose isomerization [27-29], the Cr clusters being the active Lewis acid sites. Despite highly selective to fructose, mannose has been also observed in presence of $\mathrm{Cr}$ which accounts for some glucose epimerization in addition to isomerization $[27,28]$. A product distribution of $59.3 \%$ fructose, $23.5 \%$ glucose, and $2.9 \%$ mannose has been obtained over this catalyst [28], matching the fructose yields attainable by optimized Sn-containing zeolites. The good performances over $\mathrm{Zr}$ and $\mathrm{Cr}$ containing MOFs have led to recent utilization and comparison of MOF-based catalysts with diverse porosities and Lewis acid sites $\left(\mathrm{Cr}^{3+}, \mathrm{Al}^{3+}\right.$, $\mathrm{Cu}^{2+}$, and $\mathrm{Fe}^{3+}$ ) [29]. Lara-Serrano et al. [29] have demonstrated that, in MOFs with the same structure, FeBTC has the highest conversion $(>70 \%)$ whereas MIL-53 $(\mathrm{Cr})$ has the best fructose yield. The comparison between Cr-based MOFs, MIL-53 vs. MIL-101, indicated that the higher pore size of MIL-101 induces higher fructose yields at early reaction times thus pointing out the pore size significance in glucose isomerization to fructose over MOFs-based catalysts.

Traditionally used homogeneous catalysts such as $\mathrm{AlCl}_{3}, \mathrm{CrCl}_{3}$, and $\mathrm{SnCl}_{4}$ are being currently immobilized over carbon-based supports as new approach to convert them in heterogeneous catalysts for glucose isomerization reaction [30-33]. In this way the catalysts combine the properties of homogeneous Lewis acid salts with those of carbon-based materials, being the major challenge to increase the selectivity toward useful products by suppressing the side reactions (induced by the carbonaceous support) and accelerating the desired reaction pathways. Yang et al. [30] demonstrated that pyrolysis atmosphere and temperature were key parameters to obtain highly active Sn-functionalized biochars for the isomerization of glucose to fructose. An increase of pyrolysis temperature from 650 to $850{ }^{\circ} \mathrm{C}$ in $\mathrm{N}_{2}$ resulted in the formation of more reactive metallic Sn species and increased the percentage of amorphous Sn structures, which were found to lead to higher catalytic activity. Yu et al. [31] studied the catalytic performance of aluminum-biochar composites synthesized from waste wood biomass impregnated with $\mathrm{AlCl}_{3}$. They obtained a fructose selectivity of $74 \%$ after 5 -min heating at $160{ }^{\circ} \mathrm{C}$ in acetone $/ \mathrm{H}_{2} \mathrm{O}$, being the $\mathrm{Al}$ species the major responsible of their catalytic activity. The Al sites situated on the biochar surface were found to contribute to approximately $70 \%$ of the composite activity, being the remaining $30 \%$ attributed to $\mathrm{Al}$ species leached into the solvent mixture. The preparation and catalytic activity evaluation of graphite oxide and graphene oxide impregnated with $\mathrm{AlCl}_{3}$ has been recently reported [32]. High fructose yields (34.6 mol\%) can be obtained under mild conditions, due to the presence of octahedral Al species (Lewis acid sites) and oxygen functionalities exhibiting microwave absorption. Moving a step forward in the valorization of biomass, humins from food waste biorefinery have been recently used as 
carbon precursor for the synthesis of biochar-supported Lewis $\mathrm{AlCl}_{3}$ acid catalysts [33]. Finally, $\mathrm{Sn}$ and other transition metals like $\mathrm{Co}, \mathrm{Ni}, \mathrm{Cu}$, and $\mathrm{Zr}$ have been also loaded on traditional supports such as $\mathrm{Al}_{2} \mathrm{O}_{3}$ and $\mathrm{SiO}_{2}$ for the isomerization of glucose to fructose $[34,35]$ leading to successful results.

\section{Lactic Acid Synthesis}

The production of lactic acid from glucose involves a complex process that includes several cascade reactions (Figure 3): (i) Glucose isomerization to fructose, catalyzed by Lewis acids and bases [36]; (ii) retro-aldol reaction of fructose to form glyceraldehyde (GLA) and 1,3-dihydroxyacetone (DHA) likewise catalyzed by Lewis acids and bases [37]; (iii) successive dehydration and rearrangement of DHA/GLA to form the pyruvaldehyde (PA) intermediate over both Brønsted and Lewis acid sites [38,39]; and finally (iv) a rehydration followed by 1,2-hydride shift of PA to produce LA over Lewis acids catalysts [40,41].

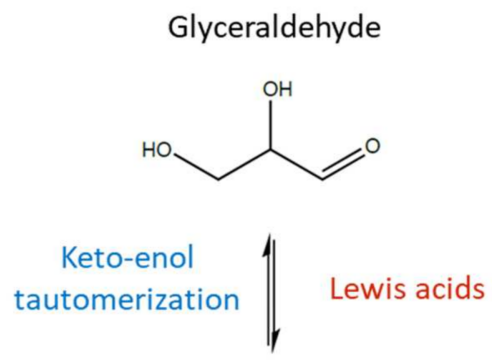

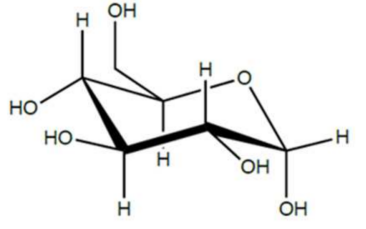

Glucose
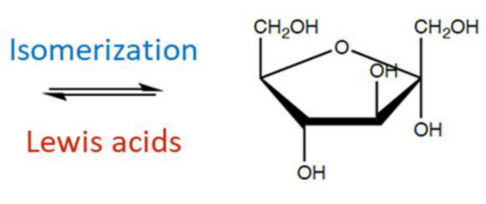

Fructose
Retro-aldolic

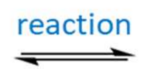

Lewis acids

\section{1,3-Dihydroxyacetone}

(DHA)<smiles>O=C(CO)CO</smiles>

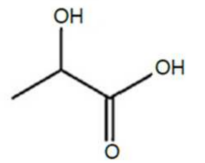

Lactic acid

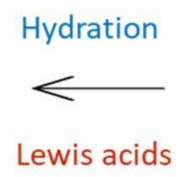

Lewis acids Dehydration $\downarrow \begin{gathered}\text { Brønsted } \\ \text { and Lewis } \\ \text { acids }\end{gathered}$

Figure 3. Brønsted/Lewis acid-catalyzed conversion of glucose to lactic acid.

The conversion of triose sugars to lactic acid was first reported by Hayashi in 2005 [42]. From that moment on many heterogeneous catalysts have been developed, including polyoxometalates [43], zeolites [44], metal oxides [45], and supported catalysts [46] among others. The trends concerning the sugar reactant has been evolving over time, the first reports have been mainly focused on triose sugar conversion (DHA/GLA) while the most recent studies are devoted to the development of multifunctional catalysts for glucose, disaccharides, or even cellulose/hemicellulose conversion to lactic acid (one-pot processes). In any case, the new trends are summarized below considering the use of triose saccharides, glucose/fructose, and other biomass feedstocks as starting reactant to produce lactic acid. 


\subsection{Triose Saccharide Conversion to Lactic Acid}

Conversion of triose sugars such as glyceraldehyde and 1,3-dihydroxyacetone in heterogeneous systems is usually carried out in water, alcohol, and/or water/alcohol mixtures in presence of solid Lewis acid catalyst. The currently used catalysts are mostly zeolites [47], $\mathrm{Nb}$ metal oxides [48,49], niobium phosphates [50], and silica supported catalysts [51]. Feliczak-Guzik et al. [47] have demonstrated that hierarchical Sn-Beta zeolite converts efficiently DHA in different solvents such as methanol, ethanol, and water with yields above $90 \%$ at $80{ }^{\circ} \mathrm{C}$ and $5 \mathrm{~h}$ reaction time. Interestingly, the authors observed that the reaction time could be reduced from $5 \mathrm{~h}$ to $1 \mathrm{~h}$ by applying microwave radiation, maintaining lactic acid/alkyl lactate yields [47].

Nakajima et al. [48] investigated the catalytic performance of niobium oxides $\left(\mathrm{Nb}_{2} \mathrm{O}_{5} \cdot \mathrm{nH}_{2} \mathrm{O}\right)$ in DHA to LA reaction. They stated that mostly two features converted these solids in promising catalysts for biomass-derived carbohydrates valorization, (i) the combination of Brønsted and Lewis acidity, since pyruvaldehyde dehydration is potentiated in presence of Brønsted acids and (ii) the unsaturated coordination sites of $\mathrm{Nb}_{2} \mathrm{O}_{5} \cdot \mathrm{nH}_{2} \mathrm{O}$ demonstrated to act as water-tolerant Lewis acid sites in water or in water/organic solvent mixtures. Based on this, the authors established that ortho- $\mathrm{Nb}_{2} \mathrm{O}_{5}$ (oxide with a deformed orthorhombic phase) having Brønsted/Lewis acidity and higher number of unsaturated water-tolerant Lewis acid sites was superior to $\mathrm{Nb}_{2} \mathrm{O}_{5} \cdot \mathrm{nH}_{2} \mathrm{O}$ in terms of lactic acid yield $(27 \%$ vs. $56 \%$ for $\mathrm{Nb}_{2} \mathrm{O}_{5} \cdot \mathrm{nH}_{2} \mathrm{O}$ and ortho- $\mathrm{Nb}_{2} \mathrm{O}_{5}$, respectively). Kim and co-workers [49] studied a slightly different niobium oxide, $\mathrm{YNbO}_{4}$, an amphoteric solid with some Lewis basicity giving higher LA yield in comparison with the reference $\mathrm{Nb}_{2} \mathrm{O}_{5}$ catalyst (74\% vs. $51 \%$ LA yield). Wang et al. [50] investigated $\mathrm{NbOPO}_{4}$ and $\mathrm{SnO}_{2}$-doped $\mathrm{NbOPO}_{4}$ catalysts with both Lewis and Brønsted acid sites and concluded that the incorporation of both $\mathrm{SnO}_{2}$ and different surfactants significantly affected the surface acidity of niobium phosphates and thus their catalytic performance. The introduction of Lewis sites $\left(\mathrm{Sn}^{4+}\right)$ boosted the pyruvaldehyde to lactic acid reaction thus the LA selectivity being higher ( $47 \%$ vs. $14 \%$ for $\mathrm{SnO}_{2}$-doped $\mathrm{NbOPO}_{4}$ and $\mathrm{NbOPO}_{4}$, respectively).

Silica-supported chromia-titania catalysts were also prepared for the selective formation of lactic acid in water [51]. Combining titanium oxide (Brønsted acid sites) and chromium oxide (Lewis acid sites) resulted in an efficient solid for selective transformation of DHA in PA and consecutively LA, with yields of up to $80 \%$.

\subsection{Glucose/Fructose Conversion to Lactic Acid}

One-pot conversion of glucose/fructose to lactic acid is a highly desired process as it constitutes a solid pathway to obtain biodegradable and biobased plastics from biomass. The number of involved sites (see Figure 3) forces the development of highly active and selective multifunctional catalysts for efficient hexoses to lactic acid conversion. Several heterogeneous acid catalysts have been applied in the last five years, including mostly zeolites [52-59], metal oxides [49,60,61], supported carbon-based materials [62], modified polyoxometalates [63], metal-organic frameworks [64], and immobilized metal triflate catalysts [53].

Zeolites, and concretely Sn-BETA, have demonstrated their high potential in biomassrelated reactions, the glucose/fructose conversion to LA being the perfect example. Under optimized reaction conditions $\left(200{ }^{\circ} \mathrm{C}, 4.0 \mathrm{MPa}\right.$ of $\left.\mathrm{He}, 30 \mathrm{~min}\right) \mathrm{Sn}$-BETA reached a lactic acid yield of $67.1 \%$ with a sugar conversion of $>98 \%$ [59]. Xia et al. have evaluated different metal-modified BETA zeolites including $\mathrm{Pb}, \mathrm{Ni}, \mathrm{Cu}$, and Ce-Sn-BETA [52] and InSn-BETA [57]. Their results showed that the catalytic activities of Sn-beta zeolite containing different metal species were substantially different [52], being the Pb-Sn-BETA sample the most suitable to produce lactic acid in comparison with $\mathrm{Ni}, \mathrm{Cu}$, and $\mathrm{Ce}$ which formed higher amounts of HMF. Under optimum reaction conditions $\left(190{ }^{\circ} \mathrm{C}\right.$ and $\left.2 \mathrm{~h}\right), \mathrm{Pb}-\mathrm{Sn}$ containing sample reached a lactic acid yield of $52 \%$ from glucose which was attributed to the key role of lead in the isomerization reactions (glucose to fructose and fructose retroaldol condensation to $\mathrm{C} 3$ intermediates) and the key role of tin in the DHA dehydration 
and PA isomerization. Additionally, lead appeared to inhibit HMF formation. The addition of In, In-Sn-BETA [57], induces a similar behavior, being 53\% the obtained lactic acid yield in the same reaction conditions $\left(190^{\circ} \mathrm{C}\right.$ and $2 \mathrm{~h}$ ). The promotion effect of $\mathrm{Mg}$ on Sn-BETA having different $\mathrm{Mg} / \mathrm{Sn}$ has been studied by Yang and co-workers [56]. They observed that both $\mathrm{Mg}^{2+}$ and $\mathrm{Sn}^{4+}$ are incorporated into BETA framework sites generating Lewis acid sites. Despite $\mathrm{Mg}^{2+}$ acid sites are weaker, it has a significant promotion effect on fructose retro-aldol reaction, the rate-determining step, and resulted in improved methyl lactate yield. The effect of adding metal promoters such as Fe [58], Zr, and Hf [55] in hierarchical Sn-BETA zeolites has been recently evaluated. Under identical conditions, doped zeolites attained much higher methyl lactate yields, suggesting that isolated Lewis acid sites are pivotal to convert glucose efficiently. The obtained catalytic activities were intimately related to their Lewis acidity. As could be expected, the hierarchical pores had a positive effect on the overall performance which was attributed to the mass transfer rates improvement. Sn- and Al-doped ultra-stable Y (USY) zeolite has been also prepared and applied in this reaction [54].

Among the possible metal oxides, $\mathrm{Nb}_{2} \mathrm{O}_{5}$ nanorod [60], $\mathrm{YNbO}_{4}$ [49], and $\mathrm{Al}_{2} \mathrm{O}_{3}, \mathrm{TiO}_{2}$, $\mathrm{ZrO}_{2} \mathrm{SnO}_{2}$, and $\mathrm{CeO}_{2}$ [61] have been recently reported for this reaction. To improve $\mathrm{Nb}_{2} \mathrm{O}_{5}$ catalytic performance, Kim et al. [60] designed orthorhombic $\mathrm{Nb}_{2} \mathrm{O}_{5}$ nanorod catalyst with improved glucose conversion and LA yield with respect to the usually employed $\mathrm{Nb}_{2} \mathrm{O}_{5}$ nanoparticles ( $24 \%$ vs. $16 \%$ for $\mathrm{Nb}_{2} \mathrm{O}_{5}$ nanorod and nanoparticles, respectively). Those results were attributed to the larger amount of Lewis acid sites of $\mathrm{Nb}_{2} \mathrm{O}_{5}$ nanorod catalyst. $\mathrm{YNbO}_{4}$ was likewise tested and compared with $\mathrm{Nb}_{2} \mathrm{O}_{5}$ [49], the obtained LA yield being $17 \%$ higher in the case of $\mathrm{YNbO}_{4}$ catalyst. Within $\mathrm{Al}_{2} \mathrm{O}_{3}, \mathrm{TiO}_{2}, \mathrm{ZrO}_{2} \mathrm{SnO}_{2}$, and $\mathrm{CeO}_{2}$ [61] metal oxides, $\mathrm{Al}_{2} \mathrm{O}_{3}$ had the best performance (LA yield $34 \%$ ) which was attributed to the highest density of both functionalities (acid and base) which are essential for the promotion of the stepwise reaction.

Murillo et al. [64] have evaluated the viability of tin-containing MOFs (UZAR-10) in sugar transformation to methyl lactate. When comparing the catalytic performances of UZAR-10 with benchmark MOFs at the same reaction conditions $\left(160^{\circ} \mathrm{C}, 20 \mathrm{~h}\right)$, methyl lactate yield of UZAR-S10 (10\%) was better than those of the HKUST-1 and MIL-101(Cr) and similar to that of UiO-66 $(9.7 \%)$.

Selective conversion of glucose into lactic acid was also investigated over ytterbium triflate immobilized on SBA-15 [53], leading to $58 \%$ LA yield at $200{ }^{\circ} \mathrm{C}$. Additionally, the authors demonstrated that the catalyst could be recycled for more than five times without noticeable loss in activity.

La-modified phosphomolybdic acid catalysts with different La/Mo atomic ratios were also evaluated [63]. The promising results, $65 \%$ of lactic acid yield over a sample with $\mathrm{La} /$ Mo ratio 0.13 , were ascribed to the good balance between Brønsted and Lewis acid sites on the catalyst. Furthermore, this potential catalyst could be reused up to five times without any loss of activity and selectivity.

Zhang and co-workers [62] have investigated the role of $\mathrm{Ni}, \mathrm{Zn}$, and activated carbon in the hydrothermal glucose conversion to lactic acid. In all cases, LA yields are improved but $\mathrm{Zn}$ was demonstrated to be the best promoter. The latter was ascribed to the capacity of $\mathrm{Zn}$ to inhibit both lactic acid decomposition and Ni oxidation which resulted essential to reach high yields. Ni had a direct catalytic role potentiated by the activated carbon which increases the contact area of the reactants. Figure 4 summarizes the most studied catalysts for glucose/fructose transformation to lactic acid. 


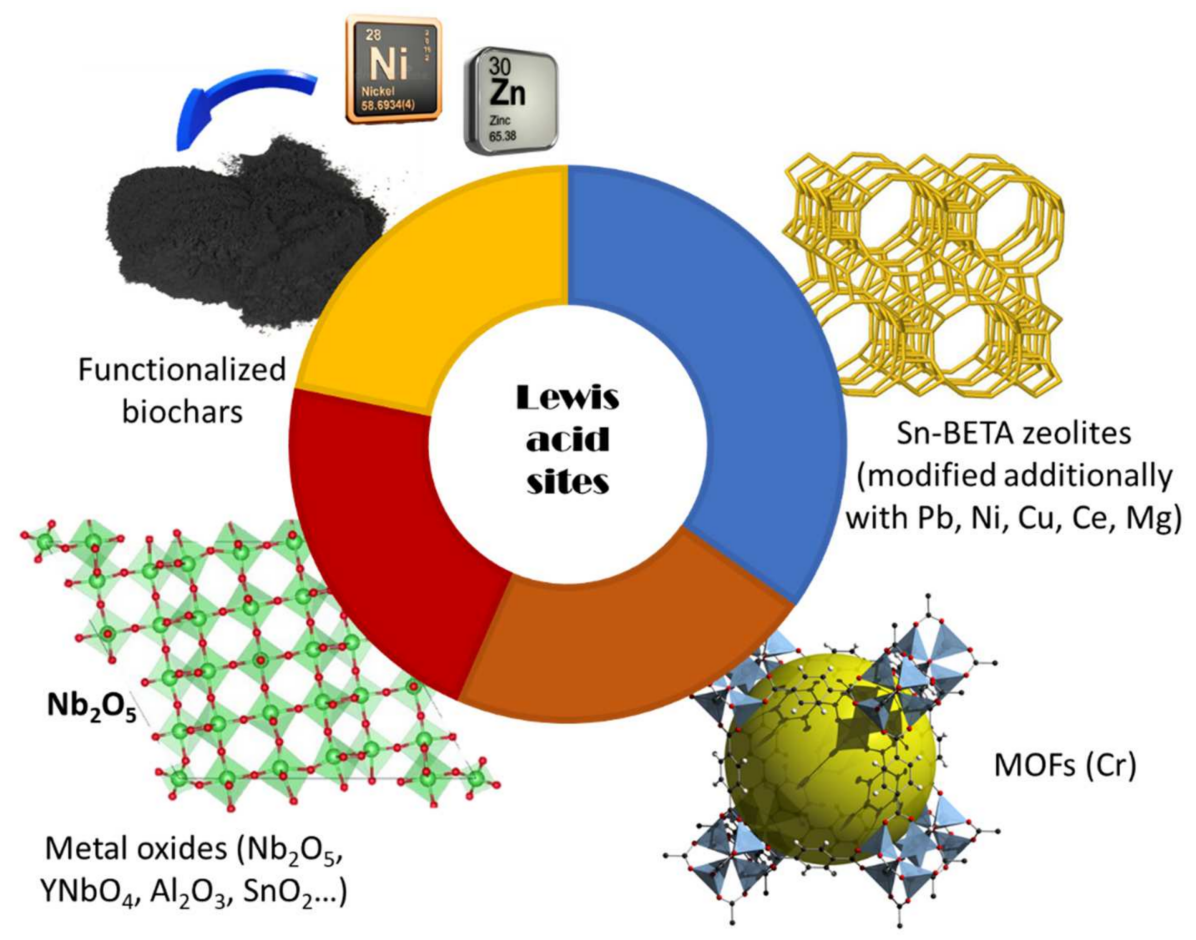

Figure 4. Involved sites and most studied catalysts for glucose/fructose transformation to lactic acid.

\subsection{Other Biomass Feedstocks to Lactic Acid}

The direct conversion of cellulose/hemicellulose into LA over heterogeneous catalysts is crucial to drive the biorefinery to industrial production of bioplastics. Apart from the number of reactions and sites (Figure 3), the efficient depolymerization of hemicellulose and/or cellulose, usually catalyzed by strong Brønsted acids, presents additional challenges. The degree of depolymerization depends on glycoside bonds accessibility, harder in the case of cellulose due to its higher crystallinity in comparison with hemicellulose or starch. Therefore, cellulose is one of the most problematic raw materials to produce lactic acid, but it is also the more convenient and available.

Metal oxides have been widely used to transform cellulose and other biomass feedstocks such as pine wood sawdust to lactic acid [65-68]. Chambon et al. [43] were pioneers in the use of tungstated zirconia $(\mathrm{ZrW})$ and alumina $(\mathrm{AlW})$ as solid Lewis acid catalysts for the direct conversion of cellulose to LA. More recently, they have used ZrW to treat both cellulose and pine wood sawdust [65] at $190^{\circ} \mathrm{C}$ in a large-scale batch reactor (2.5 L), obtaining similar kinetic curves of lactic acid formation in both cases which implies that hemicellulose/lignin fraction of the initial biomass does not prevent/deteriorate catalyst activity. Several transition metal oxides $\left(\mathrm{ZrO}_{2}, \mathrm{Al}_{2} \mathrm{O}_{3}, \mathrm{TiO}_{2}, \mathrm{Fe}_{3} \mathrm{O}_{4}, \mathrm{~V}_{2} \mathrm{O}_{5}, \mathrm{CeO}_{2}, \mathrm{Y}_{2} \mathrm{O}_{3}\right.$, $\mathrm{Tm}_{2} \mathrm{O}_{3}, \mathrm{HfO}_{2}, \mathrm{Ga}_{2} \mathrm{O}_{3}, \mathrm{MgO}, \mathrm{La}_{2} \mathrm{O}_{3}, \mathrm{Nb}_{2} \mathrm{O}_{5}$, and $\mathrm{Ta}_{2} \mathrm{O}_{5}$ ) have been also investigated for cellulose conversion in a recent study [66]. Zirconium oxide exhibited the highest catalytic activity $\left(21 \%\right.$ LA yield at $200{ }^{\circ} \mathrm{C}$ and $6 \mathrm{~h}$ ). The evaluation of different types of $\mathrm{ZrO}_{2}$ allowed the authors to find correlations between their properties and LA yields; the combination of acid and base sites appear to play a very important role in the process. The same authors explored lately the viability of $\mathrm{ZrO}_{2}-\mathrm{Al}_{2} \mathrm{O}_{3}$ catalysts as a function of $\mathrm{ZrO}_{2}$ contents [67]. They observed that LA yield increased from $21 \%$ to $25 \%$ over $10 \% \mathrm{ZrO}_{2}-\mathrm{Al}_{2} \mathrm{O}_{3}$ catalyst in comparison with pure $\mathrm{ZrO}_{2}$ which was attributed to the higher Lewis acid/base ratio. The viability of a series of $\mathrm{Nb}_{2} \mathrm{O}_{5}-\mathrm{SiO}_{2}$-coated magnetic nanoparticles for the direct conversion of cellulose has been also evaluated [68], the catalytic activity results being promising and likewise related to Lewis acid/base ratio. Verziu et al. [69] investigated Nb-based nanoscopic inorganic fluorides $\left(\mathrm{Nb} @ \mathrm{MF}_{2}\right.$ where $\left.\mathrm{M}=\mathrm{Mg}, \mathrm{Ca}\right)$ for the same reaction. They found that the acidity was significantly improved by doping $\mathrm{MgF}_{2}$ with niobium, which consequently improved the LA yield (6\% LA yield). 
Zeolites and MOFs were naturally used in one-pot conversion of cellulose (or sucrose) to lactic acid [53,64,70,71]. Wang and co-workers [71] investigated erbium-grafted H-Beta zeolites, obtaining LA yields as high as $58 \%$ at $240{ }^{\circ} \mathrm{C}$ under $2 \mathrm{MPa} \mathrm{N}_{2}$ for $30 \mathrm{~min}$. Erbium ions seemed essential to reach those LA yields, in fact the loss of activity during recycling experiments was mainly ascribed to Er leaching. Kong et al. [70] studied the sucrose conversion to lactic acid over functionalized Sn-Beta zeolite with 3-aminopropyltrimethoxysilane. The resulted catalyst had well-balanced acid-base sites which were responsible of the $58 \%$ LA yield reached under optimized hydrothermal conditions $\left(190^{\circ} \mathrm{C}, 4 \mathrm{~h}\right)$. Ytterbium triflate was immobilized on sulfo-functionalized SBA-15 zeolite and tested in cellulose to lactic acid process [53], reaching $74 \%$ of LA yield without any loss of activity during five reuse cycles (optimized conditions $220{ }^{\circ} \mathrm{C}, 2 \mathrm{MPa} \mathrm{N}_{2}$ and $60 \mathrm{~min}$ reaction time). Finally, Murillo et al. [64] demonstrated that Sn-containing MOFs (obtained after Sn metal exchange from Ti tetracarboxylate MIP-177-LT) were active in the sucrose conversion to methyl lactate, exhibiting ML yield values of $40 \%$ under optimized reaction conditions $\left(160{ }^{\circ} \mathrm{C}\right.$ for $20 \mathrm{~h}, 160 \mathrm{mg}$ of catalyst and $225 \mathrm{mg}$ of sugar).

\section{Glucose/Fructose Conversion to HMF}

Among the possible products obtained from biomass-derived hexoses, 5- hydroxymethylfurfural (HMF) constitutes another highly valuable platform chemical. Placed among the top 10 value added chemicals from biomass by the U.S. Department of Energy (DOE) [72], HMF is a versatile molecule which can be further converted into a wide range of products, and more interestingly in the case at hand, the production of bio-based plastics [73-75]. The production of HMF from glucose is a very interesting process due to the abundance and cost of the latter. However, dehydration of its isomer, fructose, to yield HMF has also attracted attention due to the highest reactivity of fructose compared to glucose. Regardless the starting hexose, the main issue for HMF production lies in controlling the selectivity. The multiple hydroxy, aldehyde, and carbonyl functional groups present in both hexoses can react, giving rise to the formation of side products [75,76]. Consequently, the control of several parameters such as catalysts' properties, employed solvent or selected reaction conditions, is essential in order to boost the catalytic performance.

\subsection{Fructose Dehydration to HMF}

The production of HMF from the triple dehydration of fructose has been widely studied and reported in the scientific literature. During the past few decades, this reaction was performed using homogeneous acid catalysts [77-79], but nowadays the trend points toward the use of heterogeneous Brønsted acid catalysts [80-82]. The selectivity toward HMF, which is highly influenced by the acidity of the catalyst, is one of the main problematic factors. Since high HMF purity is required, avoiding side reactions leading to the generation of humins or organic acids (as levulinic or formic acid) is essential [78,83]. Aside from the catalyst, the dehydration of fructose to HMF can be influenced by other factors such as the solvent nature and the reaction conditions, namely temperature and time. Generally, high fructose conversion and high HMF yield with inhibition of the formation of humins are obtained in organic reaction media, using dimethyl sulfoxide (DMSO) $[80,82,84,85]$, methyl isobutyl ketone (MIBK) [79,81,86-88] or N-methyl-2-pyrrolidone (NMP) as solvent.

Dong et al. [80] studied the effect of hyper-cross-linked polymer (HPC) catalysts functionalized with different sulfonic acid group loadings on the fructose dehydration in DMSO media. HMF yields up to $96.7 \%$ with $100 \%$ conversion were obtained after 30 min of reaction at $140{ }^{\circ} \mathrm{C}$ using a HCP-2.0 (where 2.0 represents the chlorosulfonic acid volume to $\mathrm{HCP}$ weight ratio; range studied: $1.2-4.4)$. This kind of material, presenting high pore volume and specific surface area has shown excellent performances compared to common solid acids such as MCM-41, Amberlyst- 15 , and $\mathrm{ZrO}_{2}$. SAPO-34 catalysts also functionalized by sulfonic acid group has been employed by Liu et al. [84], leading to a $72 \% \mathrm{HMF}$ yield with a complete conversion of fructose. The observed activity was explained by a synergistic effect between the $-\mathrm{SO}_{3} \mathrm{H}$ acid groups and the mesopores of the 
catalyst, while unfunctionalized SAPO-34 catalysts were less active. Bounoukta et al. [85] studied a series of sulfonated activated carbons. They found that the solvent DMSO (active in absence of catalyst) and catalyst porosity mainly rule fructose conversion while the HMF selectivity and yield depend on the active sulphonic sites strength and distribution. The p-toluene sulphonic acid is revealed as the best sulphonating agent with almost complete fructose conversions and HMF yields superior to $90 \%$, successfully maintained during five operation cycles. Pyo et al. [82] used an DR-2030 acidic ion exchange resin as catalyst. High HMF yield of $85 \%$ with $99.7 \%$ fructose conversion was obtained after $3 \mathrm{~h}$ of reaction in a batch reactor, using DMSO as solvent at $110{ }^{\circ} \mathrm{C}$. Similar results (82\% HMF yield with $98 \%$ fructose conversion) were obtained by the same authors in a solvent-free continuous flow reactor using 30\% (w/w) fructose solution as reactant [82]. Galaverna et al. [89] proposed the use of an efficient continuous flow micro-reactor using Amberlyst-15 as catalyst, which contains sulfonic acid groups located in the macropores, using an isopropyl alcohol/DMSO mixture as solvent at $110^{\circ} \mathrm{C}$. This system allowed to obtain 95\% HMF yield.

The reported results have shown that the use of organic solvents allows remarkable fructose conversion and HMF yield values. However, organic solvents as DMSO or NMP need to be extracted of the reaction mixture at the end of the reaction, which is a difficult and costly step. Indeed, DMSO is hardly volatile, possessing a boiling point of $189^{\circ} \mathrm{C}$, much higher than that of water. Moreover, the presence of sulfur in the solvent could decrease the catalytic performances of some heterogeneous catalysts due to their poisoning [90]. In order to increase the durability of the catalyst, the replacement of the DMSO used as solvent by water has been explored. In addition, this approach would make the process environmentally benign. Several heterogeneous catalysts have been used in the presence of water and interesting catalytic performances have been obtained depending on their physicochemical properties [91,92].

For instance, Antonetti et al. [91] performed the reaction in water media using niobium and zirconium phosphates ( $\mathrm{NbPO}$ and $\mathrm{ZrPO}$ ) catalysts assisted by microwave heating. A HMF yield of $40 \%$ and a fructose conversion of $96 \%$ were obtained using ZrPO catalyst at $190{ }^{\circ} \mathrm{C}$ after a short reaction time of $8 \mathrm{~min}$. According to $\mathrm{NH}_{3}$-TPD results, the $\mathrm{ZrPO}$ catalyst was presenting more acid sites than its counterpart, the $\mathrm{NbPO}$ catalyst. Furthermore, both samples were characterized by pyridine adsorption followed by FT-IR, showing equivalent concentration of Brønsted sites. While the $\mathrm{ZrPO}$ catalyst presented moderate strength Lewis acid sites, the $\mathrm{NbPO}$ catalyst showed strong Lewis acidity. However, the Lewis acid sites of $\mathrm{NbPO}$ were converted into Brønsted sites after adsorption of water, which promoted the fructose conversion but decreased the HMF selectivity by the formation of undesired products. Additionally, the authors demonstrated that the catalyst could be recycled three times without noticeable loss in activity.

Although the use of water as solvent presents important advantages, the degradation of HMF in this media constitutes an important issue. To solve this, biphasic systems using water and an organic solvent have been also employed in recent years in order to improve the HMF yield from the dehydration of fructose [78,79,81,88,90,93]. This system has shown to be effective for a better extraction of HMF from the organic phase, which prevents the degradation of the product [78]. Moreover, after HMF separation, the organic solvent can be recycled and reused in the system. Guangqiang et al. [86] studied the fructose dehydration both in aqueous media and in a MIBK/water biphasic system over two silica-induced heteropolyacids $\left(\mathrm{HPAs} / \mathrm{SiO}_{2}\right)$ as catalyst. In particular, phosphotungstic acid (HPW) and tungstosilicic acid (HSiW) supported on $\mathrm{SiO}_{2}$ were evaluated. Both solids were characterized by $\mathrm{NH}_{3}-\mathrm{TPD}$, pointing out that $\mathrm{HPW} / \mathrm{SiO}_{2}$ presented a greater density of strong acid sites than $\mathrm{HSiW} / \mathrm{SiO}_{2}$ and similar weak acid sites density. Furthermore, $\mathrm{HPW} / \mathrm{SiO}_{2}$ had medium acidity while its counterpart did not. The fructose conversion was promoted by the strong acid properties of $\mathrm{HPW} / \mathrm{SiO}_{2}$, but formation of humins could occur, thus lowering the HMF yield. Testa et al. [94] studied different syntheses of functionalized $\mathrm{TiO}_{2}-\mathrm{SO}_{3} \mathrm{H}$ catalysts for the $\mathrm{HMF}$ production from fructose. The simple method to prepare the $\mathrm{TiO}_{2}-\mathrm{SO}_{3} \mathrm{H}$ solid, which consisted of slow chlorosulfonic acid 
solution addition to a $\mathrm{TiO}_{2}$ power allowed a 50\% HMF yield with a complete fructose conversion after $3 \mathrm{~h}$ of reaction at $165^{\circ} \mathrm{C}$ using 1:1 water/organic (3:7 sec-BuOH/MIBK). More recently, Mayer et al. [81] obtained HMF yields up to 59\% with a fructose conversion of $99 \%$ after $2 \mathrm{~h}$ of reaction at $150{ }^{\circ} \mathrm{C}$ using pyrochlores $\left(\mathrm{H}_{3} \mathrm{O}\right)_{1.25} \mathrm{Sb}_{1.25} \mathrm{Te}_{(0.75)} \mathrm{O}_{6}$ catalyst in water/MIBK with the conclusion that the amount of $\mathrm{H}_{3} \mathrm{O}^{+}$is directly related to the activity obtained.

The dehydration of fructose has been also studied in solvent and metal free conditions by Shaikh et al. [95], using graphene oxide (GO) as the heterogeneous catalyst. The reaction was performed by sonication to obtain an intimate mixture of the GO and the fructose, which reached an almost complete fructose conversion of $90 \%$ with a $78.3 \% \mathrm{HMF}$ yield at $100{ }^{\circ} \mathrm{C}$ for $5 \mathrm{~h}$. A possible mechanism was proposed, suggesting successive interactions between the acidic group of $\mathrm{GO}$ and the $-\mathrm{OH}$ groups of fructose, which liberated water molecules through proton transfer processes. Delgado et al. [88] also proposed functionalized nanographitic carbon as a catalyst for fructose conversion to HMF in $\mathrm{MIBK} / \mathrm{H}_{2} \mathrm{O}$ biphasic system. The functionalization affects the catalyst' structural and textural properties but results in an increasing number of Brønsted acid sites reflecting in a very good selectivity to $\mathrm{HMF}(74 \%$ in $12 \mathrm{~h})$; the latter improved by changing the substrate/catalyst ratio. The catalysts showed an excellent reusability and maintained HMF selectivity in five successive cycles. Furthermore, Karimi et al. [96] studied the synthesis of magnetic catalysts, such as $\mathrm{SiO}_{2} @ \mathrm{Fe}_{3} \mathrm{O}_{4}$ with different functionalization, as $-\mathrm{SO}_{3} \mathrm{H}$ and -dendrimer group addition in order to easily extract the solid of the reaction media. The authors obtained up to $92 \% \mathrm{HMF}$ yield in $1 \mathrm{~h}$ at $100{ }^{\circ} \mathrm{C}$, using a $\mathrm{SO}_{3} \mathrm{H}-$ dendrimer- $\mathrm{SiO}_{2} @ \mathrm{Fe}_{3} \mathrm{O}_{4}$ catalyst in a solvent-free system with a deep eutectic mixture of sucrose/fructose $(1: 1, \mathrm{~mol} / \mathrm{mol})$. Recyclability tests showed the possibility to obtain an almost inexistent loss of catalytic performances, with a small HMF yield decrease from 92 to $89 \%$.

As a general trend, research on the fructose dehydration reaction has focused on the importance of the strength and quantity of the acid sites present in the catalyst, regardless the used reaction media. The reported results bring to light the importance to find an equilibrium regarding the strong acid sites concentration in order to promote the fructose conversion without degrading HMF or promoting side reactions.

\subsection{Glucose Conversion to HMF}

Although HMF can be produced with high yields from fructose, HMF synthesis from glucose is a more attractive process, considering the abundance and low cost of the latter [97]. Direct production of HMF from glucose takes place via two steps: glucose isomerization to fructose followed by fructose dehydration (Figure 5). The first step is favored by Lewis acid sites, whereas the second takes place in presence of Brønsted acid sites. Nevertheless, Brønsted acid functionalities hinder the isomerization reaction, whereas excess of Lewis acid sites leads to the formation of undesired by-products. Hence, the onepot conversion of glucose to HMF is a challenging process in which tailoring the catalyst acidity becomes crucial [98-101]. In this sense, both homogeneous and heterogeneous acid catalysts have been widely studied. However, heterogeneous catalysts are preferred due to their environmental advantages and the easier separation of the reaction products and catalyst [102] and a great variety of heterogeneous catalysts have been developed in the last five years for the direct conversion of glucose into HMF. 


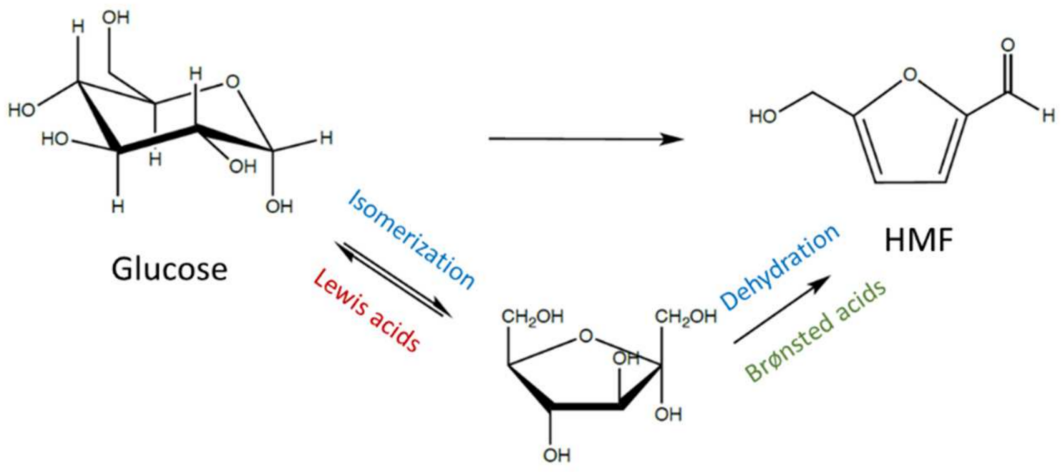

Fructose

Figure 5. Brønsted/Lewis acid catalyzed conversion of glucose to HMF.

Metal oxides, as materials par excellence in heterogeneous catalysis, have been extensively studied. AlNb/SBA-15 catalysts have been tested in the conversion of glucose to $\mathrm{HMF}$ using $\mathrm{MIBK} / \mathrm{H}_{2} \mathrm{O}$ as solvent mixture [103]. By varying the $\mathrm{Al} / \mathrm{Nb}$ atomic ratios, the strength and quantity of Brønsted and Lewis acid sites were successfully tuned. The highest glucose conversion (93.4\%) and HMF yield (55.7\%) were attained with the $\mathrm{Al}_{0.40} \mathrm{Nb}_{0.60} / \mathrm{SBA}-15$ catalyst at $170{ }^{\circ} \mathrm{C}$ after $6 \mathrm{~h}$ of reaction, which was attributed to the highest total acidity and balance of Brønsted and Lewis acid sites. The same catalyst was re-used four times with no significant loss of activity, thus suggesting that the catalyst was stable. Supported $\mathrm{B}_{2} \mathrm{O}_{3} / \mathrm{ZrO}_{2}-\mathrm{Al}_{2} \mathrm{O}_{3}$ (BZA) containing Brønsted and Lewis acid sites were also tested for the HMF production from glucose [104]. In this study, reaction parameters and catalyst composition were optimized. The BZA- 0.20 catalyst containing a $20 \%$ of $\mathrm{B}_{2} \mathrm{O}_{3}$ showed the best results, converting $90.8 \%$ of glucose with a $41.2 \%$ HMF yield in 4 $\mathrm{h}$ of reaction at $150{ }^{\circ} \mathrm{C}$. The results were attributed to the higher specific surface area and suitable Brønsted and Lewis acidity of this solid with respect to its BZA counterparts.

Another strategy to tune the oxides' acid properties consists of the functionalization of the oxide surfaces with acid groups. Li et al. [102] proposed a sophisticated synthetic method for the preparation of PDA- $\mathrm{MnO}_{2} @ S n P C P$ composites. Using 5-suplhoisophthalic acid as ligand, the authors synthesized a tin porous coordination polymer (SnPCP) on the surface of polydopamine-coated $\mathrm{MnO}_{2}$. After $5 \mathrm{~h}$ of reaction in DMSO, 92.3\% of glucose was converted with a $55.8 \%$ yield of $\mathrm{HMF}$, higher than the values observed for SnPCP alone $(63.7 \%$ glucose conversion and $39.4 \%$ HMF yield). The enhanced performance of the composite was ascribed to a synergistic effect of SnPCP and $\mathrm{MnO}_{2}-\mathrm{PDA}$, a balanced control of the Brønsted and Lewis acid sites and a smaller pore size and higher specific surface area of PDA-MnO $\mathrm{MnSnPCP}_{2}$ with respect to SnPCP. Phosphated $\mathrm{TiO}_{2}\left(\mathrm{P}-\mathrm{TiO}_{2}\right)$ catalysts also showed good results for effectively converting glucose into HMF in the presence of $\mathrm{NaCl}$ using a water/THF mixture as solvent [105]. Catalysts with a $15 \%$ phosphate loading achieved the most promising results, with a glucose conversion of $98.5 \%$ and a HMF yield of $53.5 \%$ after $2 \mathrm{~h}$ of reaction at $175{ }^{\circ} \mathrm{C}$. The excellent performance was explained by the high acidity, large BET surface area and pore volume, and the presence of strong Brønsted and Lewis acid functionalities in the solid. Following the same principle, functionalized mixed oxides have been proposed in the literature. Phosphotungstic acidified titaniumzirconium dioxides $\left(\mathrm{HPA} / \mathrm{TiO}_{2}-\mathrm{ZrO}_{2}\right.$ ) have been evaluated using a $\mathrm{NaCl}_{(\mathrm{aq})} / \mathrm{THF}$ biphasic system [106]. Several parameters such as $\mathrm{HPA}$ loading, $\mathrm{TiO}_{2} / \mathrm{ZrO}_{2}$ ratio, stirring rate, temperature, catalyst loading, and ratio of the biphasic components were evaluated. After optimization of the catalyst composition and reaction parameters, a HMF yield of 51.3\% was achieved after $4 \mathrm{~h}$ at $160{ }^{\circ} \mathrm{C}$, using a $5 \% \mathrm{HPA} / \mathrm{TiO}_{2}-\mathrm{ZrO}_{2}$ catalyst. Higher acid loadings gave rise to a decrease in the yield of $\mathrm{HMF}$, pointing out the importance of controlling the acid sites density in the catalyst.

The use of bare phosphates has also been suggested. However, control of the acidity is even more complicated in this type of materials, due to the strong acidity of the $\mathrm{PO}_{4}{ }^{-}$ 
groups. In this sense, Vieira and co-workers [107] reported the use of niobium phosphate in monophasic solvent systems, which is more advantageous than the biphasic systems for industrial application. The authors found an increase of the L/B (Lewis-to-Brønsted) ratio with the decrease of the $\mathrm{P} / \mathrm{Nb}$ molar ratio. Additionally, a linear correlation between the $\mathrm{L} / \mathrm{B}$ ratio and the reaction rate during the one-pot conversion of glucose to $\mathrm{HMF}$ was established. Silica-supported phosphate and iron phosphate catalysts $\left(\mathrm{H}_{3} \mathrm{PO}_{4}-\mathrm{SiO}_{2}-\mathrm{FePO}_{4}\right)$ with different $\mathrm{H}_{3} \mathrm{PO}_{4}$ and $\mathrm{FePO}_{4}$ loadings have also shown promising results, explained by a synergistic effect of the Brønsted $\mathrm{H}_{3} \mathrm{PO}_{4}$ and Lewis $\mathrm{FePO}_{4}$ functionalities [108].

Zeolites and MOFs have been explored since they possess both Brønsted and Lewis acid sites and their structures can be tuned as needed. For instance, Zhang et al. [98] combined a Sn- $\beta$ zeolite containing Lewis acid sites with a heterogeneous Brønsted acid solid prepared through the copolymerization of $p$-toluenesulfonic acid (PTSA) and paraformaldehyde (POM). The best catalytic performance was obtained using a $0.5 \mathrm{Sn}-\beta$-to PTSA-POM mass ratio and $0.4 \mathrm{~g}$ of glucose at $140{ }^{\circ} \mathrm{C}$, using a $\gamma$-valerolactone (GVL)/water mixture as solvent. After $30 \mathrm{~min}$, a conversion of $96.3 \%$ and a HMF yield of $60.1 \%$ were achieved. The excellent results were explained by the optimization of the Lewis-to-Brønsted acid sites ratio and the capacity of GVL to solubilize the formed humins, thus avoiding their deposition on the catalyst surface. A $5 \%$ Sn/SAPO-34 zeolite prepared by impregnation [109] has shown a $98.5 \%$ glucose conversion with a $64.4 \% \mathrm{HMF}$ yield at $150{ }^{\circ} \mathrm{C}$ after $1.5 \mathrm{~h}$ of reaction. The zeolite modification with Sn allowed to decrease the acid strength of the parent zeolite and obtain an appropriate Lewis-to-Brønsted acid sites ratio. These characteristics allowed the catalytic system to be reused four times without loss of catalytic performance.

Modification of MOFs by different strategies have shown that introduction of structural defects, particle size tailoring, or incorporation of functional groups allows an improvement of the catalytic performance with respect to the parent MOFs. For instance, a series of UiO-66 materials with different structural modifications permitted to perform the reaction even in continuous flow, which make them interesting for industrial application [110]. Tangsermvit et al. [111] modified the structure of sulphonated UiO-66 through the addition of $\mathrm{Al}^{3+}$. The catalyst achieved complete glucose conversion with a HMF yield of $63 \%$ at $120{ }^{\circ} \mathrm{C}$ in DMSO/water. DFT calculations suggested that the results were a consequence of the presence of adjacent Brønsted and Lewis acid sites, which promoted the catalytic reaction.

Finally, the use of carbon-based materials has attracted great attention in the last years. $\mathrm{Al}_{2} \mathrm{O}_{3}-\mathrm{TiO}_{2}$ modified sulfonated carbon with hierarchically ordered pores (SCHOP) have shown interesting results [112]. Using $\mathrm{Al}_{2} \mathrm{O}_{3} / \mathrm{TiO}_{2}$ mass ratio of $2: 1$, a suitable combination of Brønsted and Lewis acid functionalities was obtained, allowing to reach a high HMF selectivity of $96 \%$ after $3 \mathrm{~h}$ of reaction at $130{ }^{\circ} \mathrm{C}$. Following a similar strategy, bifunctional Lewis/Brønsted tandem carbon catalysts of p-toluenesulfonic acid (pTSA)functionalized activated carbon (AC) impregnated with $\mathrm{CaCl}_{2}$ or $\mathrm{ZnCl}_{2}$ were tested in the direct conversion of glucose to HMF [87]. The presence of only Lewis sites orients the reaction via glucose-to-fructose isomerization and following dehydration to HMF while the presence of Brønsted sites (- $\mathrm{SO}_{3} \mathrm{H}$ from the pTSA) directs the reaction to HMF through levoglucosan intermediate. The occurrence of both sites allows the simultaneous tworoute HMF production but catalyzes also the humins production via HMF-glucose cross polymerization suggesting that catalysts with higher Lewis/Bronsted acidity are needed to achieve moderate HMF yield without excessive carbon loss. Figure 6 compiles the involved sites and the most studied catalysts for glucose conversion into HMF in the last years.

Although promising results have been obtained using different types of catalysts, a direct comparison between them is not possible due to the great variety of catalysts' nature, solvents, and reaction conditions reported in the literature. However, the obtained results allow to conclude that the most challenging aspect during this reaction is to selectively convert the glucose into HMF, avoiding the production of undesirable products. In order to achieve that, it is especially important the control of the catalyst acidity and the selection of the solvent and reaction conditions, which generally determine the selectivity trend. 


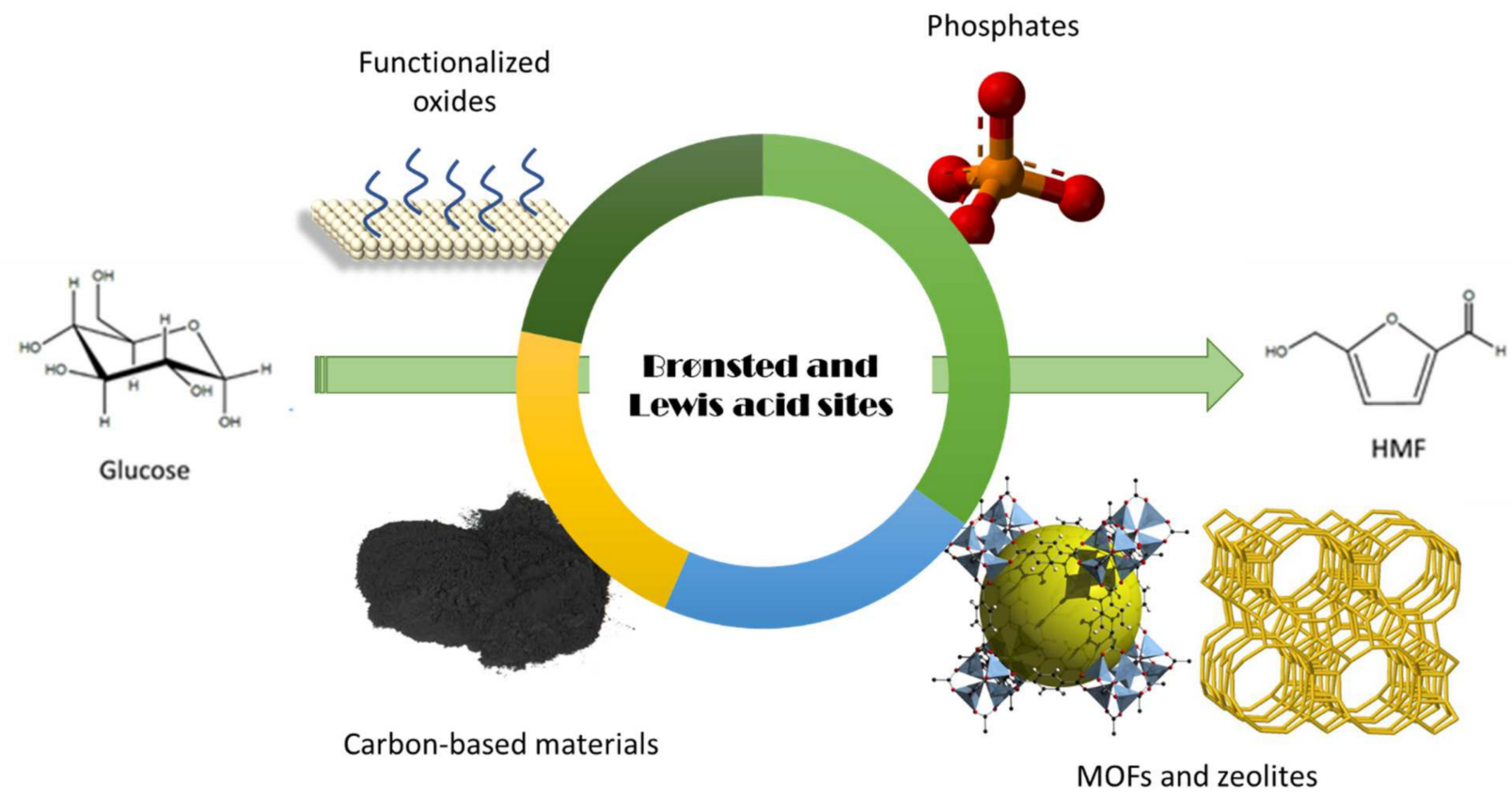

Figure 6. Involved sites and most studied catalysts for glucose conversion into HMF.

\subsection{Other Biomass Feedstocks to HMF}

The direct catalytic conversion of cellulose or hemicellulose into HMF is also a very interesting approach and takes place in two steps: the acid-catalyzed hydrolysis of the carbohydrate into glucose or xylose followed by the oxidative cleavage of C-C bonds to produce the organic acid [113]. For the first step, solid acid catalysts have been proposed to substitute the typically used homogeneous mineral acids. For the second step, however, the control over oxidation ability of the catalyst is essential. Over-oxidation of both, glucose and xylose provokes combustion of the monosaccharides by producing $\mathrm{CO}_{2}$ and water. Consequently, a combination of an acid catalyst able to perform the first step together with a metal catalyst to control the oxidation ability has been generally proposed [114]. However, recent research starts exploring new non-conventional materials to perform the direct conversion of cellulose into HMF.

For instance, sulphonated poly(phenylene) sulfide (SPPS) catalysts have shown excellent results for HMF production from cellulose using ionic liquids as solvent, yielding $68.2 \%$ of HMF [115]. In this system, the $\mathrm{SO}_{3} \mathrm{H}$ group of SPPS acts as a Brønsted acid, whereas the ILs used as solvent are thought to stabilize the reaction intermediates implied in HMF formation.

The use of boehmite $(\gamma-\mathrm{AlOOH})$ has been reported to convert $97.2 \%$ of cellulose with a 58.4\% HMF yield. Although the reason of the observed catalytic performance is not clear, the catalyst only presented Lewis acid sites but not Brønsted acid functionality, which suggests that the presence of the latter is not necessary to achieve a high cellulose conversion and moderate HMF selectivity [116].

Metal oxides $\left(\mathrm{TiO}_{2}\right.$ and $\left.\mathrm{ZrO}_{2}\right)$ in the presence of $\mathrm{CO}_{2}$ also showed promising catalytic results [117]. In this case, $\mathrm{CO}_{2}$ plays a key role since it gives rise to the in situ generation of carbonic acid, which remarkably enhanced the HMF yield (48.4\%) with respect to the bare oxides.

Different types of zeolites have also been investigated. The yield of HMF has demonstrated to be dependent on the $\mathrm{SiO}_{2} / \mathrm{Al}_{2} \mathrm{O}_{3}$ ratio, and the addition of $\mathrm{Cr}$ to the zeolite structure showed an enhancement of the selectivity toward HMF formation [118].

Regardless of the employed catalyst, HMF yields from cellulose are always below to those obtained from glucose or fructose. 


\section{Conclusions and Future Perspectives}

The great functionality of the biomass molecules, either poly/oligomers or monomers, opens an important spectrum of possibilities to convert them into useful products that can be further upgraded. We can use hydrogenation and hydrodeoxygenation reactions to obtain fuels/solvents or fuels additives or we can also dehydrate and oxidize directly or after C-C cleavage to obtain several monomers for bioplastic production. No matter the route of valorization, several cascade reactions are usually involved for which different active sites are required. The conversion of glucose to fructose, HMF, or lactic acid requires the presence of Lewis sites and/or Bronsted sites for isomerization, retro aldolic, and dehydration reactions, respectively. Nevertheless, the excess of sites in number and strength, Bronsted or Lewis, provokes a drop in selectivity due to their participation in secondary reactions. That is why, the combination of both sites usually moderates the reaction rates and inhibits the formation of humins and that presents the first main challenge-successful catalyst design. The final product determines the route of platform molecule transformation and the combination of active sites, while for HMF production Bronsted sites must prevail, for lactic acid and fructose production greater number of Lewis sites are required. Although a great work made, up to date, on a multifunctional Brønsted/Lewis acid catalytic system there is an urgent need of fundamental studies on their interaction in between and/or with the support. The sites titration (number and/or strength) and optimal Brønsted/Lewis ratio evaluation is another pending subject within the field. We can also add to the list the detailed study of Lewis sites behavior in aqueous or biphasic media. Regarding the starting molecules, fructose is better represented but still voids must be filled concerning catalyst design and reaction optimization using glucose as reactive. Even bigger challenges such as converting directly the higher weight biopolymers are to be overcome. The conditions of their hydrolysis could influence greatly the nature of the selected catalysts and transform it in less performant for the rest of involved cascade reactions. Finally, the control of the secondary reactions needs a serious improvement in order to increase the overall efficiency of all processes related to the use of biomolecule for high value-added products synthesis.

Author Contributions: All authors have contributed to the writing-original draft preparation and writing-review and editing. All authors have read and agreed to the published version of the manuscript.

Funding: This work was supported by the Spanish Ministry of Science, Innovation and Universities (REF FJC2018-037162-I), the French Research National Agency (REF ANR-20-CE43-0014) and Junta de Andalucía PAIDI 2020 program (REF P18-RT-3405).

Data Availability Statement: Not applicable.

Acknowledgments: C. Megías-Sayago acknowledges financial support from the Spanish Ministry of Science, Innovation and Universities through Juan de la Cierva Formación Fellowship with REF FJC2018-037162-I. S. Navarro-Jaén acknowledges the financial support provided by the French Research National Agency (ANR) through the INGENCat project (ANR-20-CE43-0014). S. Ivanova acknowledges Junta de Andalucía PAIDI 2020 program and its financial support for the project with P18-RT-3405 reference.

Conflicts of Interest: The authors declare no conflict of interest.

\section{References}

1. Celik, G.; Kennedy, R.M.; Hackler, R.A.; Ferrandon, M.; Tennakoon, A.; Patnaik, S.; Lapointe, A.M.; Ammal, S.C.; Heyden, A.; Perras, F.A.; et al. Upcycling Single-Use Polyethylene into High-Quality Liquid Products. ACS Cent. Sci. 2019, 5, 1795-1803. [CrossRef] [PubMed]

2. Rahman, M.H.; Bhoi, P.R. An overview of non-biodegradable bioplastics. J. Clean. Prod. 2021, 294, 126218. [CrossRef]

3. World Economic Forum, Ellen MacArthur Foundation and McKinsey \& Company. The New Plastic Economy. Rethinking the Future of Plastics. 2016. Available online: http:/ / www.ellenmacarthurfoundation.org/publications (accessed on 30 October 2021).

4. Degli Esposti, M.; Morselli, D.; Fava, F.; Bertin, L.; Cavani, F.; Viaggi, D.; Fabbri, P. The role of biotechnology in the transition from plastics to bioplastics: An opportunity to reconnect global growth with sustainability. FEBS Open Bio 2021, 11, 967-983. [CrossRef] 
5. De Vargas Mores, G.; Finocchio, C.P.S.; Barichello, R.; Pedrozo, E.A. Sustainability and innovation in the Brazilian supply chain of green plastic. J. Clean. Prod. 2018, 177, 12-18. [CrossRef]

6. Mika, L.T.; Cséfalvay, E.; Németh, A. Catalytic Conversion of Carbohydrates to Initial Platform Chemicals: Chemistry and Sustainability. Chem. Rev. 2018, 118, 505-613. [CrossRef] [PubMed]

7. Megías-Sayago, C.; Navarro-Jaén, S.; Castillo, R.; Ivanova, S. Recent advances in selective oxidation of biomass-derived platform chemicals over gold catalysts. Curr. Opin. Green Sustain. Chem. 2020, 21, 50-55. [CrossRef]

8. Besson, M.; Gallezot, P.; Pinel, C. Conversion of Biomass into Chemicals over Metal Catalysts. Chem. Rev. 2014, 114, 1827-1870. [CrossRef] [PubMed]

9. Kim, M.; Su, Y.; Aoshima, T.; Fukuoka, A.; Hensen, E.J.M.; Nakajima, K. Effective Strategy for High-Yield Furan Dicarboxylate Production for Biobased Polyester Applications. ACS Catal. 2019, 9, 4277-4285. [CrossRef]

10. Burgess, S.K.; Leisen, J.E.; Kraftschik, B.E.; Mubarak, C.R.; Kriegel, R.M.; Koros, W.J. Chain Mobility, Thermal, and Mechanical Properties of Poly(ethylene furanoate) Compared to Poly(ethylene terephthalate). Macromolecules 2014, 47, 1383-1391. [CrossRef]

11. Delidovich, I.; Hausoul, P.J.C.; Deng, L.; Pfützenreuter, R.; Rose, M.; Palkovits, R. Alternative Monomers Based on Lignocellulose and Their Use for Polymer Production. Chem. Rev. 2016, 116, 1540-1599. [CrossRef]

12. Nofar, M.; Sacligil, D.; Carreau, P.J.; Kamal, M.R.; Heuzey, M.-C. Poly (lactic acid) blends: Processing, properties and applications. Int. J. Biol. Macromol. 2019, 125, 307-360. [CrossRef]

13. Murariu, M.; Dubois, P. PLA composites: From production to properties. Adv. Drug Deliv. Rev. 2016, 107, 17-46. [CrossRef]

14. Xu, S.; Wu, Y.; Li, J.; He, T.; Xiao, Y.; Zhou, C.; Hu, C. Directing the Simultaneous Conversion of Hemicellulose and Cellulose in Raw Biomass to Lactic Acid. ACS Sustain. Chem. Eng. 2020, 8, 4244-4255. [CrossRef]

15. Havstad, M.R. Biodegradable plastics. In Plastic Waste and Recycling; Elsevier: Amsterdam, The Netherlands, 2020; pp. 97-129.

16. Son, P.A.; Nishimura, S.; Ebitani, K. Preparation of zirconium carbonate as water-tolerant solid base catalyst for glucose isomerization and one-pot synthesis of levulinic acid with solid acid catalyst. React. Kinet. Mech. Catal. 2014, 111, 183-197. [CrossRef]

17. Bhosale, S.H.; Rao, M.B.; Deshpande, V.V. Molecular and industrial aspects of glucose isomerase. Microbiol. Rev. 1996, 60, 280-300. [CrossRef] [PubMed]

18. Gounder, R.; Davis, M.E. Monosaccharide and disaccharide isomerization over Lewis acid sites in hydrophobic and hydrophilic molecular sieves. J. Catal. 2013, 308, 176-188. [CrossRef]

19. Moliner, M.; Román-Leshkov, Y.; Davis, M.E. Tin-containing zeolites are highly active catalysts for the isomerization of glucose in water. Proc. Natl. Acad. Sci. USA 2010, 107, 6164-6168. [CrossRef] [PubMed]

20. Román-Leshkov, Y.; Moliner, M.; Labinger, J.A.; Davis, M.E. Mechanism of Glucose Isomerization Using a Solid Lewis Acid Catalyst in Water. Angew. Chem. Int. Ed. 2010, 49, 8954-8957. [CrossRef]

21. Cordon, M.J.; Hall, J.N.; Harris, J.W.; Bates, J.S.; Hwang, S.J.; Gounder, R. Deactivation of Sn-Beta zeolites caused by structural transformation of hydrophobic to hydrophilic micropores during aqueous-phase glucose isomerization. Catal. Sci. Technol. 2019, 9, 1654-1668. [CrossRef]

22. Yang, H.; Guo, Q.; Yang, P.; Liu, X.; Wang, Y. Synthesis of hierarchical Sn-Beta zeolite and its catalytic performance in glucose conversion. Catal. Today 2021, 367, 117-123. [CrossRef]

23. Leus, K.; Bogaerts, T.; De Decker, J.; Depauw, H.; Hendrickx, K.; Vrielinck, H.; Van Speybroeck, V.; Van Der Voort, P. Systematic study of the chemical and hydrothermal stability of selected "stable" Metal Organic Frameworks. Microporous Mesoporous Mater. 2016, 226, 110-116. [CrossRef]

24. Oozeerally, R.; Burnett, D.L.; Chamberlain, T.W.; Walton, R.I.; Degirmenci, V. Exceptionally Efficient and Recyclable Heterogeneous Metal-Organic Framework Catalyst for Glucose Isomerization in Water. ChemCatChem 2018, 10, 706-709. [CrossRef] [PubMed]

25. De Mello, M.D.; Tsapatsis, M. Selective Glucose-to-Fructose Isomerization over Modified Zirconium UiO-66 in Alcohol Media. ChemCatChem 2018, 10, 2417-2423. [CrossRef]

26. Rojas-Buzo, S.; Corma, A.; Boronat, M.; Moliner, M. Unraveling the reaction mechanism and active sites of metal-organic frameworks for glucose transformations in water: Experimental and theoretical studies. ACS Sustain. Chem. Eng. 2020, 8 , 16143-16155. [CrossRef]

27. Luo, Q.X.; Zhang, Y.B.; Qi, L.; Scott, S.L. Glucose Isomerization and Epimerization over Metal-Organic Frameworks with Single-Site Active Centers. ChemCatChem 2019, 11, 1903-1909. [CrossRef]

28. Guo, Q.; Ren, L.; Kumar, P.; Cybulskis, V.J.; Mkhoyan, K.A.; Davis, M.E.; Tsapatsis, M. A Chromium Hydroxide/MIL-101(Cr) MOF Composite Catalyst and Its Use for the Selective Isomerization of Glucose to Fructose. Angew. Chem. 2018, 130, $5020-5024$. [CrossRef]

29. Lara-Serrano, M.; Morales-delaRosa, S.; Campos-Martin, J.M.; Abdelkader-Fernández, V.K.; Cunha-Silva, L.; Balula, S.S. Isomerization of glucose to fructose catalyzed by metal-organic framework. Sustain. Energy Fuels in press. 2021. [CrossRef]

30. Yang, X.; Yu, I.K.M.; Cho, D.W.; Chen, S.S.; Tsang, D.C.W.; Shang, J.; Yip, A.C.K.; Wang, L.; Ok, Y.S. Tin-Functionalized Wood Biochar as a Sustainable Solid Catalyst for Glucose Isomerization in Biorefinery. ACS Sustain. Chem. Eng. 2019, 7, 4851-4860. [CrossRef]

31. Yu, I.K.M.; Xiong, X.; Tsang, D.C.W.; Wang, L.; Hunt, A.J.; Song, H.; Shang, J.; Ok, Y.S.; Poon, C.S. Aluminium-biochar composites as sustainable heterogeneous catalysts for glucose isomerisation in a biorefinery. Green Chem. 2019, 21, 1267-1281. [CrossRef] 
32. Yu, I.K.M.; Xiong, X.; Tsang, D.C.W.; Ng, Y.H.; Clark, J.H.; Fan, J.; Zhang, S.; Hu, C.; Ok, Y.S. Graphite oxide- and graphene oxide-supported catalysts for microwave-assisted glucose isomerisation in water. Green Chem. 2019, 21, 4341-4353. [CrossRef]

33. Xiong, X.; Yu, I.K.M.; Dutta, S.; Mašek, O.; Tsang, D.C.W. Valorization of humins from food waste biorefinery for synthesis of biochar-supported Lewis acid catalysts. Sci. Total Environ. 2021, 775, 1-8. [CrossRef] [PubMed]

34. Yu, I.K.M.; Hanif, A.; Tsang, D.C.W.; Yip, A.C.K.; Lin, K.Y.A.; Gao, B.; Ok, Y.S.; Poon, C.S.; Shang, J. Tailoring acidity and porosity of alumina catalysts via transition metal doping for glucose conversion in biorefinery. Sci. Total Environ. 2020, 704, 135414. [CrossRef] [PubMed]

35. Palai, Y.N.; Shrotri, A.; Asakawa, M.; Fukuoka, A. Silica supported Sn catalysts with tetrahedral Sn sites for selective isomerization of glucose to fructose. Catal. Today 2021, 365, 241-248. [CrossRef]

36. Kumar, S.; Nepak, D.; Kansal, S.K.; Elumalai, S. Expeditious isomerization of glucose to fructose in aqueous media over sodium titanate nanotubes. RSC Adv. 2018, 8, 30106-30114. [CrossRef]

37. Orazov, M.; Davis, M.E. Tandem catalysis for the production of alkyl lactates from ketohexoses at moderate temperatures. Proc. Natl. Acad. Sci. USA 2015, 112, 11777-11782. [CrossRef]

38. Rasrendra, C.B.; Fachri, B.A.; Makertihartha, I.G.; Adisasmito, S.; Heeres, H.J. Catalytic conversion of dihydroxyacetone to lactic acid using metal salts in water. ChemSusChem 2011, 4, 768-777. [CrossRef]

39. Taarning, E.; Saravanamurugan, S.; Holm, M.S.; Xiong, J.; West, R.M.; Christensen, C.H. Zeolite-catalyzed isomerization of triose sugars. ChemSusChem 2009, 2, 625-627. [CrossRef]

40. Koito, Y.; Nakajima, K.; Kitano, M.; Hara, M. Efficient conversion of pyruvic aldehyde into lactic acid by Lewis acid catalyst in water. Chem. Lett. 2013, 42, 873-875. [CrossRef]

41. Li, L.; Stroobants, C.; Lin, K.; Jacobs, P.A.; Sels, B.F.; Pescarmona, P.P. Selective conversion of trioses to lactates over Lewis acid heterogeneous catalysts. Green Chem. 2011, 13, 1175-1181. [CrossRef]

42. Hayashi, Y.; Sasaki, Y. Tin-catalyzed conversion of trioses to alkyl lactates in alcohol solution. Chem. Commun. 2005, 36, 2716-2718. [CrossRef]

43. Chambon, F.; Rataboul, F.; Pinel, C.; Cabiac, A.; Guillon, E.; Essayem, N. Cellulose hydrothermal conversion promoted by heterogeneous Brønsted and Lewis acids: Remarkable efficiency of solid Lewis acids to produce lactic acid. Appl. Catal. B Environ. 2011, 105, 171-181. [CrossRef]

44. Ennaert, T.; Van Aelst, J.; Dijkmans, J.; De Clercq, R.; Schutyser, W.; Dusselier, M.; Verboekend, D.; Sels, B.F. Potential and challenges of zeolite chemistry in the catalytic conversion of biomass. Chem. Soc. Rev. 2016, 47, 584-611. [CrossRef]

45. Jeon, W.; Ban, C.; Park, G.; Woo, H.C.; Kim, D.H. Hydrothermal conversion of macroalgae-derived alginate to lactic acid catalyzed by metal oxides. Catal. Sci. Technol. 2015, 6, 1146-1156. [CrossRef]

46. Zhang, S.; Jin, F.; Hu, J.; Huo, Z. Improvement of lactic acid production from cellulose with the addition of Zn/Ni/C under alkaline hydrothermal conditions. Biores. Technol. 2011, 102, 1998-2003. [CrossRef] [PubMed]

47. Feliczak-Guzik, A.; Sprynskyy, M.; Nowak, I.; Buszewski, B. Catalytic isomerization of dihydroxyacetone to lactic acid and alkyl lactates over hierarchical zeolites containing tin. Catalysts 2018, 8, 31. [CrossRef]

48. Nakajima, K.; Hirata, J.; Kim, M.; Gupta, N.K.; Murayama, T.; Yoshida, A.; Hiyoshi, N.; Fukuoka, A.; Ueda, W. Facile Formation of Lactic Acid from a Triose Sugar in Water over Niobium Oxide with a Deformed Orthorhombic Phase. ACS Catal. 2018, 8, 283-290. [CrossRef]

49. Kim, M.; Ronchetti, S.; Onida, B.; Ichikuni, N.; Fukuoka, A.; Kato, H.; Nakajima, K. Lewis Acid and Base Catalysis of YNbO4 Toward Aqueous-Phase Conversion of Hexose and Triose Sugars to Lactic Acid in Water. ChemCatChem 2020, 12, 350-359. [CrossRef]

50. Wang, X.; Song, Y.; Huang, C.; Wang, B. Crystalline niobium phosphates with water-tolerant and adjustable Lewis acid sites for the production of lactic acid from triose sugars. Sustain. Energy Fuels 2018, 2, 1530-1541. [CrossRef]

51. Takagaki, A.; Goto, H.; Kikuchi, R.; Oyama, S.T. Silica-supported chromia-titania catalysts for selective formation of lactic acid from a triose in water. Appl. Catal. A Gen. 2019, 570, 200-208. [CrossRef]

52. Xia, M.; Dong, W.; Gu, M.; Chang, C.; Shen, Z.; Zhang, Y. Synergetic effects of bimetals in modified beta zeolite for lactic acid synthesis from biomass-derived carbohydrates. RSC Adv. 2018, 8, 8965-8975. [CrossRef]

53. Wang, S.; Chen, K.; Wang, Q. Ytterbium triflate immobilized on sulfo-functionalized SBA-15 catalyzed conversion of cellulose to lactic acid. J. Porous Mater. 2018, 25, 1531-1539. [CrossRef]

54. Iglesias, J.; Moreno, J.; Morales, G.; Melero, J.A.; Juárez, P.; López-Granados, M.; Mariscal, R.; Martínez-Salazar, I. Sn-Al-USY for the valorization of glucose to methyl lactate: Switching from hydrolytic to retro-aldol activity by alkaline ion exchange. Green Chem. 2019, 21, 5876-5885. [CrossRef]

55. Tang, B.; Li, S.; Song, W.C.; Yang, E.C.; Zhao, X.J.; Guan, N.; Li, L. Fabrication of Hierarchical Sn-Beta Zeolite as Efficient Catalyst for Conversion of Cellulosic Sugar to Methyl Lactate. ACS Sustain. Chem. Eng. 2020, 8, 3796-3808. [CrossRef]

56. Yang, X.; Lv, B.; Lu, T.; Su, Y.; Zhou, L. Promotion effect of Mg on a post-synthesized Sn-Beta zeolite for the conversion of glucose to methyl lactate. Catal. Sci. Technol. 2020, 10, 700-709. [CrossRef]

57. Xia, M.; Dong, W.; Shen, Z.; Xiao, S.; Chen, W.; Gu, M.; Zhang, Y. Efficient production of lactic acid from biomass-derived carbohydrates under synergistic effects of indium and tin in In-Sn-Beta zeolites. Sustain. Energy Fuels 2020, 4, 5327-5338. [CrossRef] 
58. Cai, Q.; Yue, X.; Dong, W.S. Hierarchical Fe-Sn/Beta catalyzes the conversion of glucose to methyl lactate. J. Porous Mater. 2021, 28, 1315-1324. [CrossRef]

59. Sun, Y.; Shi, L.; Wang, H.; Miao, G.; Kong, L.; Li, S.; Sun, Y. Efficient production of lactic acid from sugars over Sn-Beta zeolite in water: Catalytic performance and mechanistic insights. Sustain. Energy Fuels 2019, 3, 1163-1171. [CrossRef]

60. Cao, D.; Cai, W.; Tao, W.; Zhang, S.; Wang, D.; Huang, D. Lactic Acid Production from Glucose Over a Novel Nb2O5 Nanorod Catalyst. Catal. Lett. 2017, 147, 926-933. [CrossRef]

61. Yamaguchi, S.; Yabushita, M.; Kim, M.; Hirayama, J.; Motokura, K.; Fukuoka, A.; Nakajima, K. Catalytic Conversion of BiomassDerived Carbohydrates to Methyl Lactate by Acid-Base Bifunctional $\gamma-\mathrm{Al}_{2} \mathrm{O}_{3}$. ACS Sustain. Chem. Eng. 2018, 6, 8113-8117. [CrossRef]

62. Zhang, S.; Jin, F.; Hu, J.; Zhang, W. Role of metallic Zn, Ni and activated carbon additives in improving the hydrothermal conversion of glucose into lactic acid. J. Chem. Technol. Biotechnol. 2017, 92, 1046-1052. [CrossRef]

63. Zhao, B.; Yue, X.; Li, H.; Li, J.; Liu, C.L.; Xu, C.; Dong, W.S. Lanthanum-modified phosphomolybdic acid as an efficient catalyst for the conversion of fructose to lactic acid. React. Kinet. Mech. Catal. 2018, 125, 55-69. [CrossRef]

64. Murillo, B.; Zornoza, B.; de la Iglesia, O.; Wang, S.; Serre, C.; Téllez, C.; Coronas, J. Tin-Carboxylate MOFs for Sugar Transformation into Methyl Lactate. Eur. J. Inorg. Chem. 2019, 2624-2629. [CrossRef]

65. Swesi, Y.; Nguyen, C.; Ha Vu, T.T.; Rataboul, F.; Eternot, M.; Fongarland, P.; Essayem, N. Direct Solid Lewis Acid Catalyzed Wood Liquefaction into Lactic Acid: Kinetic Evidences that Wood Pretreatment Might Not be a Prerequisite. ChemCatChem 2017, 9 , 2377-2382. [CrossRef]

66. Wattanapaphawong, P.; Reubroycharoen, P.; Yamaguchi, A. Conversion of cellulose into lactic acid using zirconium oxide catalysts. RSC Adv. 2017, 7, 18561-18568. [CrossRef]

67. Wattanapaphawong, P.; Sato, O.; Sato, K.; Mimura, N.; Reubroycharoen, P.; Yamaguchi, A. Conversion of cellulose to lactic acid by using $\mathrm{ZrO}_{2}-\mathrm{Al}_{2} \mathrm{O}_{3}$ catalysts. Catalysts 2017, 7, 221. [CrossRef]

68. Candu, N.; Anita, F.; Podolean, I.; Cojocaru, B.; Parvulescu, V.I.; Coman, S.M. Direct conversion of cellulose to $\alpha$-hydroxy acids (AHAs) over $\mathrm{Nb}_{2} \mathrm{O}_{5}-\mathrm{SiO}_{2}$-coated magnetic nanoparticles. Green Process. Synth. 2017, 6, 255-264. [CrossRef]

69. Verziu, M.; Serano, M.; Jurca, B.; Parvulescu, V.I.; Coman, S.M.; Scholz, G.; Kemnitz, E. Catalytic features of Nb-based nanoscopic inorganic fluorides for an efficient one-pot conversion of cellulose to lactic acid. Catal. Today 2018, 306, 102-110. [CrossRef]

70. Kong, L.; Shen, Z.; Zhang, W.; Xia, M.; Gu, M.; Zhou, X.; Zhang, Y. Conversion of Sucrose into Lactic Acid over Functionalized Sn-Beta Zeolite Catalyst by 3-Aminopropyltrimethoxysilane. ACS Omega 2018, 3, 17430-17438. [CrossRef] [PubMed]

71. Wang, F.F.; Wu, H.Z.; Ren, H.F.; Liu, C.L.; Xu, C.L.; Dong, W.S. Er/ $\beta$-zeolite-catalyzed one-pot conversion of cellulose to lactic acid. J. Porous Mater. 2017, 24, 697-706. [CrossRef]

72. Werpy, T.; Petersen, G. Top Value Added Chemicals from Biomass; National Renewable Energy Lab.: Golden, CO, USA, 2004; Volume I. [CrossRef]

73. Sheldon, R.A. Green and sustainable manufacture of chemicals from biomass: State of the art. Green Chem. 2014, 16, 950-963 [CrossRef]

74. Davidson, M.G.; Elgie, S.; Parsons, S.; Young, T.J. Production of HMF, FDCA and their derived products: A review of life cycle assessment (LCA) and techno-economic analysis (TEA) studies. Green Chem. 2021, 23, 3154-3171. [CrossRef]

75. Van Putten, R.J.; Van Der Waal, J.C.; De Jong, E.; Rasrendra, C.B.; Heeres, H.J.; De Vries, J.G. Hydroxymethylfurfural, a versatile platform chemical made from renewable resources. Chem. Rev. 2013, 113, 1499-1597. [CrossRef]

76. Zhu, L.; Fu, X.; Hu, Y.; Hu, C. Controlling the Reaction Networks for Efficient Conversion of Glucose into 5-Hydroxymethylfurfural. ChemSusChem 2020, 13, 4812-4832. [CrossRef] [PubMed]

77. Körner, P.; Jung, D.; Kruse, A. The effect of different Brønsted acids on the hydrothermal conversion of fructose to HMF. Green Chem. 2018, 20, 2231-2241. [CrossRef]

78. Guo, W.; Zhang, Z.; Hacking, J.; Heeres, H.J.; Yue, J. Selective fructose dehydration to 5-hydroxymethylfurfural from a fructoseglucose mixture over a sulfuric acid catalyst in a biphasic system: Experimental study and kinetic modelling. Chem. Eng. J. 2021, 409, 128182. [CrossRef]

79. Cao, Z.; Li, M.; Chen, Y.; Shen, T.; Tang, C.; Zhu, C.; Ying, H. Dehydration of fructose into 5-hydroxymethylfurfural in a biphasic system using EDTA as a temperature-responsive catalyst. Appl. Catal. A Gen. 2019, 569, 93-100. [CrossRef]

80. Dong, K.; Zhang, J.; Luo, W.; Su, L.; Huang, Z. Catalytic conversion of carbohydrates into 5-hydroxymethyl furfural over sulfonated hyper-cross-linked polymer in DMSO. Chem. Eng. J. 2018, 334, 1055-1064. [CrossRef]

81. Mayer, S.F.; Falcón, H.; Dipaola, R.; Ribota, P.; Moyano, L.; Morales-delaRosa, S.; Mariscal, R.; Campos-Martín, J.M.; Alonso, J.A.; Fierro, J.L.G. Dehydration of fructose to HMF in presence of $(\mathrm{H} 3 \mathrm{O}) \mathrm{xSbxTe}(2-\mathrm{x}) \mathrm{O} 6(\mathrm{x}=1,1.1,1.25)$ in $\mathrm{H}_{2} \mathrm{O}-\mathrm{MIBK}$. Mol. Catal. 2020, 481, 110276. [CrossRef]

82. Pyo, S.H.; Sayed, M.; Hatti-Kaul, R. Batch and Continuous Flow Production of 5-Hydroxymethylfurfural from a High Concentration of Fructose Using an Acidic Ion Exchange Catalyst. Org. Process Res. Dev. 2019, 23, 952-960. [CrossRef]

83. Wojcieszak, R.; Itabaiana, I. Engineering the future: Perspectives in the 2,5-furandicarboxylic acid synthesis. Catal. Today 2020, 354, 211-217. [CrossRef]

84. Liu, Z.; Sun, Z.; Qin, D.; Yang, G. Sulfonic acid-functionalized hierarchical SAPO-34 for fructose dehydration to 5hydroxymethylfurfural. React. Kinet. Mech. Catal. 2019, 128, 523-538. [CrossRef] 
85. Bounoukta, C.E.; Megías-Sayago, C.; Ivanova, S.; Penkova, A.; Ammari, F.; Centeno, M.A.; Odriozola, J.A. Effect of the sulphonating agent on the catalytic behavior of activated carbons in the dehydration reaction of fructose in DMSO. Appl. Catal. A Gen. 2021, 617, 118108. [CrossRef]

86. Lv, G.; Deng, L.; Lu, B.; Li, J.; Hou, X.; Yang, Y. Efficient dehydration of fructose into 5-hydroxymethylfurfural in aqueous medium over silica-included heteropolyacids. J. Clean. Prod. 2017, 142, 2244-2251. [CrossRef]

87. Bounoukta, C.E.; Megías-Sayago, C.; Ammari, F.; Ivanova, S.; Monzon, A.; Centeno, M.A.; Odriozola, J.A. Dehydration of glucose to 5-Hydroxymethlyfurfural on bifunctional carbon catalysts. Appl. Catal. B Environ. 2021, 286, 119938. [CrossRef]

88. Delgado Martín, G.; Bounoukta, C.E.; Ammari, F.; Domínguez, M.I.; Monzón, A.; Ivanova, S.; Centeno, M.A. Fructose dehydration reaction over functionalized nanographitic catalysts in MIBK/H2O biphasic system. Catal. Today 2021, 366, 68-76. [CrossRef]

89. Galaverna, R.; Breitkreitz, M.C.; Pastre, J.C. Conversion of d-Fructose to 5-(Hydroxymethyl)furfural: Evaluating Batch and Continuous Flow Conditions by Design of Experiments and In-Line FTIR Monitoring. ACS Sustain. Chem. Eng. 2018, 6, 4220-4230. [CrossRef]

90. Sayed, M.; Warlin, N.; Hulteberg, C.; Munslow, I.; Lundmark, S.; Pajalic, O.; Tunå, P.; Zhang, B.; Pyo, S.H.; Hatti-Kaul, R. 5-Hydroxymethylfurfural from fructose: An efficient continuous process in a water-dimethyl carbonate biphasic system with high yield product recovery. Green Chem. 2020, 22, 5402-5413. [CrossRef]

91. Antonetti, C.; Melloni, M.; Licursi, D.; Fulignati, S.; Ribechini, E.; Rivas, S.; Parajó, J.C.; Cavani, F.; Raspolli Galletti, A.M. Microwave-assisted dehydration of fructose and inulin to HMF catalyzed by niobium and zirconium phosphate catalysts. Appl. Catal. B Environ. 2017, 206, 364-377. [CrossRef]

92. Wang, C.; Gong, W.; Lu, X.; Xiang, Y.; Ji, P. Heparin Immobilized on Multiwalled Carbon Nanotubes for Catalytic Conversion of Fructose in Water with High Yield and Selectivity. ACS Omega 2019, 4, 16808-16815. [CrossRef]

93. Yan, P.; Xia, M.; Chen, S.; Han, W.; Wang, H.; Zhu, W. Unlocking biomass energy: Continuous high-yield production of 5-hydroxymethylfurfural in water. Green Chem. 2020, 22, 5274-5284. [CrossRef]

94. Testa, M.L.; Miroddi, G.; Russo, M.; Parola, V.L.; Marcì, G. Dehydration of fructose to 5-HMF over acidic TiO 2 catalysts. Materials 2020, 13, 1178. [CrossRef]

95. Shaikh, M.; Singh, S.K.; Khilari, S.; Sahu, M.; Ranganath, K.V.S. Graphene oxide as a sustainable metal and solvent free catalyst for dehydration of fructose to 5-HMF: A new and green protocol. Catal. Commun. 2018, 106, 64-67. [CrossRef]

96. Karimi, S.; Shekaari, H.; Halimehjani, A.Z.; Niakan, M. Solvent-Free Production of 5-Hydroxymethylfurfural from Deep Eutectic Substrate Reaction Mixtures over a Magnetically Recoverable Solid Acid Catalyst. ACS Sustain. Chem. Eng. 2021, 9, 326-336. [CrossRef]

97. Tomer, R.; Biswas, P. Dehydration of glucose/fructose to 5-hydroxymethylfurfural (5-HMF) over an easily recyclable sulfated titania $\left(\mathrm{SO}_{2}-/ \mathrm{TiO}_{2}\right)$ catalyst. New J. Chem. 2020, 44, 20734-20750. [CrossRef]

98. Zhang, T.; Fan, W.; Li, W.; Xu, Z.; Xin, H. One-Pot Conversion of Carbohydrates into 5-(Hydroxymethyl ) furfural using Heterogeneous Lewis-Acid and Brønsted-Acid Catalysts. Energy Technol. 2017, 5, 747-755. [CrossRef]

99. Takagaki, A.; Ohara, M.; Nishimura, S.; Ebitani, K. A one-pot reaction for biorefinery : Combination of solid acid and base catalysts for direct production of 5-hydroxymethylfurfural from saccharides. Chem. Commun. 2009, 41, 6276-6278. [CrossRef]

100. Nikolla, E.; Rom, Y.; Moliner, M.; Davis, M.E. “One-Pot” Synthesis of 5-(Hydroxymethyl)furfural from Carbohydrates using Tin-Beta Zeolite. Acs Catal. 2011, 1, 408-410. [CrossRef]

101. Catrinck, M.N.; Ribeiro, E.S.; Monteiro, R.S.; Ribas, R.M.; Barbosa, M.H.P.; Teófilo, R.F. Direct conversion of glucose to 5hydroxymethylfurfural using a mixture of niobic acid and niobium phosphate as a solid acid catalyst. Fuel 2017, 210, 67-74. [CrossRef]

102. Li, K.; Du, M.; Ji, P. Multifunctional Tin-Based Heterogeneous Catalyst for Catalytic Conversion of Glucose to 5Hydroxymethylfurfural. ACS Sustain. Chem. Eng. 2018, 6, 5636-5644. [CrossRef]

103. Wang, Y.; Zhu, L.; Zhang, Y.; Cui, H.; Yi, W.; Song, F.; Zhao, P.; Sun, X.; Xie, Y.; Wang, L.; et al. AlNb/SBA-15 Catalysts with Tunable Lewis and Bronsted Acidic Sites for Glucose Conversion to HMF. ChemistrySelect 2018, 3, 3555-3560. [CrossRef]

104. Han, B.; Zhao, P.; He, R.; Wu, T.; Wu, Y. Catalytic Conversion of Glucose to 5-Hydroxymethyfurfural Over B2O3 Supported Solid Acids Catalysts. Waste Biomass Valorization 2018, 9, 2181-2190. [CrossRef]

105. Rao, K.T.V.; Souzanchi, S.; Yuan, Z.; Xu, C. One-pot sol-gel synthesis of a phosphated TiO2 catalyst for conversion of monosaccharide, disaccharides, and polysaccharides to 5-hydroxymethylfurfural. New J. Chem. 2019, 43, 12483-12493. [CrossRef]

106. He, R.; Huang, X.; Zhao, P.; Han, B.; Wu, T.; Wu, Y. The Synthesis of 5-Hydroxymethylfurfural from Glucose in Biphasic System by Phosphotungstic Acidified Titanium-Zirconium Dioxide. Waste Biomass Valorization 2018, 9, 657-668. [CrossRef]

107. Vieira, J.L.; Paul, G.; Iga, G.D.; Cabral, N.M.; Bueno, J.M.C.; Bisio, C.; Gallo, J.M.R. Niobium phosphates as bifunctional catalysts for the conversion of biomass-derived monosaccharides. Appl. Catal. A Gen. 2021, 617, 118099. [CrossRef]

108. Huang, F.; Su, Y.; Long, Z.; Chen, G.; Yao, Y. Enhanced Formation of 5-Hydroxymethylfurfural from Glucose Using a SilicaSupported Phosphate and Iron Phosphate Heterogeneous Catalyst. Ind. Eng. Chem. Res. 2018, 57, 10198-10205. [CrossRef]

109. Song, X.; Yue, J.; Zhu, Y.; Wen, C.; Chen, L.; Liu, Q.; Ma, L.; Wang, C. Efficient Conversion of Glucose to 5-Hydroxymethylfurfural over a Sn-Modified SAPO-34 Zeolite Catalyst. Ind. Eng. Chem. Res. 2021, 60, 5838-5851. [CrossRef]

110. Oozeerally, R.; Burnett, D.L.; Chamberlain, T.W.; Kashtiban, R.J.; Huband, S.; Walton, R.I.; Degirmenci, V. Systematic Modification of UiO-66 Metal-Organic Frameworks for Glucose Conversion into 5-Hydroxymethyl Furfural in Water. ChemCatChem 2021, 13, 2517-2529. [CrossRef] 
111. Tangsermvit, V.; Pila, T.; Boekfa, B.; Somjit, V.; Klysubun, W.; Limtrakul, J.; Horike, S.; Kongpatpanich, K. Incorporation of $\mathrm{Al}^{3+}$ Sites on Brønsted Acid Metal-Organic Frameworks for Glucose-to-Hydroxylmethylfurfural Transformation. Small 2021, 17, 2006541. [CrossRef] [PubMed]

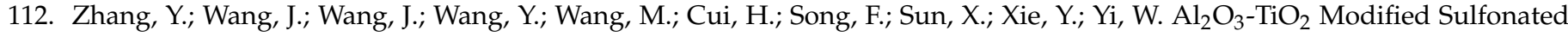
Carbon with Hierarchically Ordered Pores for Glucose Conversion to 5-HMF. ChemistrySelect 2019, 4, 5724-5731. [CrossRef]

113. Li, X.; Zhang, L.; Wang, S.; Wu, Y. Recent Advances in Aqueous-Phase Catalytic Conversions of Biomass Platform Chemicals Over Heterogeneous Catalysts. Front. Chem. 2020, 7, 948. [CrossRef]

114. Gliozzi, G.; Innorta, A.; Mancini, A.; Bortolo, R.; Perego, C.; Ricci, M.; Cavani, F. Zr/P/O catalyst for the direct acid chemohydrolysis of non-pretreated microcrystalline cellulose and softwood sawdust. Appl. Catal. B Environ. 2014, 145, 24-33. [CrossRef]

115. Li, Z.; Su, K.; Ren, J.; Yang, D.; Cheng, B.; Kim, C.K.; Yao, X. Direct catalytic conversion of glucose and cellulose. Green Chem. 2018, 20, 863-872. [CrossRef]

116. Tang, Z.; Su, J. Direct conversion of cellulose to 5-hydroxymethylfurfural (HMF) using an efficient and inexpensive boehmite catalyst. Carbohydr. Res. 2019, 481, 52-59. [CrossRef] [PubMed]

117. Jing, S.; Cao, X.; Zhong, L.; Peng, X.; Sun, R.; Liu, J. Effectively enhancing conversion of cellulose to HMF by combining in-situ carbonic acid from CO2 and metal oxides. Ind. Crop. Prod. 2018, 126, 151-157. [CrossRef]

118. Sezgin, E.; Esen Keçeci, M.; Akmaz, S.; Koc, S.N. Heterogeneous Cr-zeolites (USY and Beta) for the conversion of glucose and cellulose to 5-hydroxymethylfurfural (HMF). Cellulose 2019, 26, 9035-9043. [CrossRef] 